Alma Mater Studiorum - Università di Bologna DEPARTMENT OF ECONOMICS

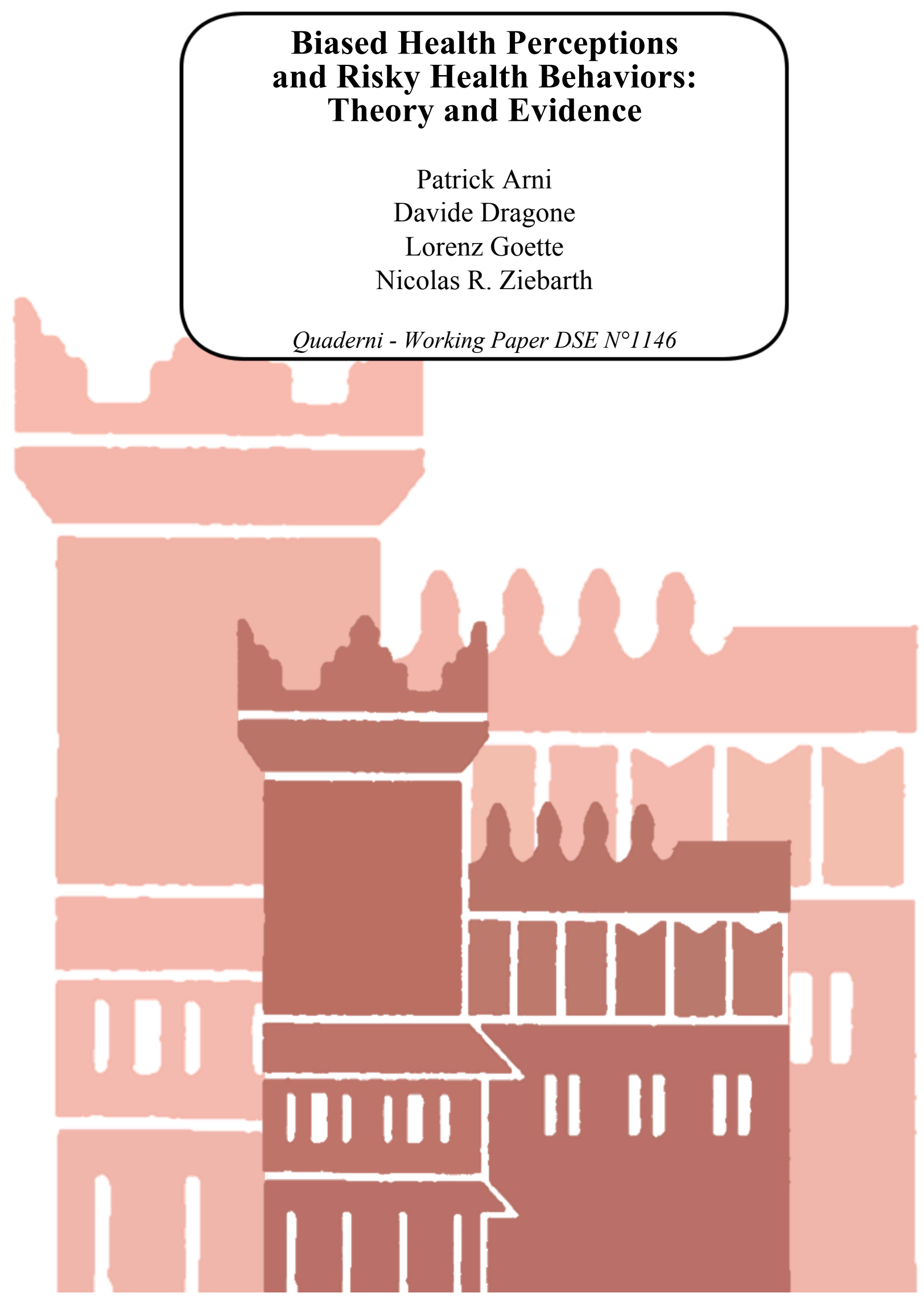




\title{
Biased Health Perceptions and Risky Health Behaviors-Theory and Evidence
}

\author{
Patrick Arni \\ University of Bristol
}

\author{
Davide Dragone \\ University of Bologna \\ Nicolas R. Ziebarth \\ Cornell University *
}

April 23, 2020

\author{
Lorenz Goette \\ University of Bonn
}

\begin{abstract}
This paper investigates the role of biased health perceptions as driving forces of risky health behavior. We define absolute and relative health perception biases, illustrate their measurement in surveys and provide evidence on their relevance. Next, we decompose the theoretical effect into its extensive and intensive margin: When the extensive margin dominates, people (wrongly) believe they are healthy enough to "afford" unhealthy behavior. Finally, using three population surveys, we provide robust empirical evidence that respondents who overestimate their health are less likely to exercise and sleep enough, but more likely to eat unhealthily and drink alcohol daily.
\end{abstract}

Keywords: health bias, health perceptions, subjective beliefs, overconfidence, underconfidence, overoptimism, risky behavior, smoking, obesity, exercising, SF12, SAH, BASE-II

JEL classification: C93, D03, D83, I12

\footnotetext{
${ }^{\ddagger}$ We would like to thank Teresa Bago d’Uva, Michele Belot, Kitt Carpenter, John Cawley, Davide Cesarini, Resul Cesur, Owen O’Donnell, Fabrice Etilé, Osea Giuntella, Glenn Harrison, Ben Hansen, Hendrik Jüerges, Jonathan Ketcham, Nadine Ketel, Gaurav Khanna, Audrey Laporte, Fabian Lange, Taryn Morrissey, Robert Nuscheler, Reto Odermatt, Ricardo Perez-Truglia, Gregor Pfeifer, Pia Pinger, Aldo Rustichini, Joe Sabia, Luis Santos Pinto, Tom Siedler, Rodrigo Soares, Pascal St-Amour, Alois Stutzer, Justin Sydnor, Harald Tauchmann, Erdal Tekin, Christian Traxler, Gerard van den Berg, Ben Vollaard, Justin White, Véra Zabrodina. In particular we thank our discussants Matt Harris and Nathan Kettlewell for excellent comments and suggestions. Moreover, we thank conference participants at the the 2019 iHEA World Congress in Basel, the 2019 Workshop on the Economics of Risky Behavior in Bologna, the 2018 ASHEcon meetings in Atlanta, 2017 Bristol Workshop on Economic Policy Interventions and Behaviour, the 2017 Risky Health Behaviors Workshop in Hamburg, the 2014 iHEA/ECHE conference in Dublin as well as seminar participants at the University of Basel, University of Reno, the Berlin Network of Labor Market Research (BeNA), and The Institute on Health Economics, Health Behaviors and Disparities at Cornell University. We take responsibility for all remaining errors in and shortcomings of the article. This article uses data from the Innovation Panel of the Socio-Economic Panel Study (SOEP-IP) as well as the Berlin Aging Study II (BASE-II). BASE-II has been supported by the German Federal Ministry of Education and Research and Research under grant numbers 16SV5537/16SV55837/16SV5538/16SV5536K/01UW0808. We also would like to thank Peter Eibich and Katrin Schaar for excellent support with the BASE-II data, David Richter for his excellent support with the SOEP-IP data as well as Gert Wagner for his overall support of this research and with the BASE-II and SOEP-IP data. The research reported in this paper is not the result of a for-pay consulting relationship. The responsibility for the contents of this publication lies with its authors. Our employers do not have a financial interest in the topic of the paper that might constitute a conflict of interest. The project has been exempt from Cornell IRB review under ID \# 1309004122.

${ }^{*}$ Corresponding author: Cornell University, Department of Policy Analysis and Management (PAM), 426 Kennedy Hall, Ithaca, NY 14850, USA, phone: +1-(607)255-1180, e-mail: nrz2 e cornell . edu
} 


\title{
Biased Health Perceptions and Risky Health Behaviors:
}

\section{Theory and Evidence}

\author{
by Patrick Arni, Davide Dragone, Lorenz Goette and Nicolas R. Ziebarth
}

\section{NON-TECHNICAL SUMMARY}

Can risky health behavior be "optimal"? Does overconfidence or optimism about our own health affect our decision to smoke, eat, or exercise? Do people behave differently when they think they are healthier than they actually are? Perhaps surprisingly, these questions have not been investigated thoroughly in the health economics literature.

The economics literature has defined and measured "overconfidence" in many different ways. A common definition considers overconfidence as an overestimation of own performance or characteristics. Accordingly, it means that a person believes, for instance, to be smarter, more skilled, or more competent than she actually is. An alternative but related definition considers overconfidence as an individual assessment relative to other people. Accordingly, it means that a person overestimates her own ability, skills, or performance relative to a reference group. A third definition considers overconfidence in terms of the accuracy or precision of information. In the context of health, the first notion implies that a person believes to be healthier than she actually is; the second implies that a person believes to be healthier than her reference group, and the third implies that a person is overly certain that her perceived health is the true health.

In this paper, we investigate theoretically and empirically the first and second notions, which we define as biases in absolute and relative health perceptions. We show that the two definitions are closely related and that one maps into the other under plausible assumptions. To measure absolute health perception biases, we use clinically diagnosed health conditions about high cholesterol and high blood pressure and how survey respondents' perceptions about having such a condition deviate from the facts. Using a representative German survey, we find that $30 \%$ of the population has biased perceptions about their high cholesterol levels.

To measure relative health perception biases, specifically for this research, we asked respondents to rank their health status relative to a reference group. Using two different high-quality surveys from Germany, we find that many respondents believe that, out of 100 people, there are (only) between 10 and 30 people in better health, a finding that is mathematically impos- 
sible. We find that about a third of respondents believe that there are only 30 people in better health than them, whereas in reality there are 60 people.

Next, we show theoretically that health perception biases affect health-related behavior through two possible channels. These operate in opposite directions. The first channel emphasizes the role of perceived health; the second channel emphasizes the role of the perceived costs of unhealthy behavior. The former implies that the more a person (wrongly) believes to be healthy, the more she engages in unhealthy behavior because she thinks she can "afford "it. The latter, instead, implies an overestimation of the costs of unhealthy behavior. Accordingly, the higher the perception of her health, the less willing a person is to jeopardize her health; and therefore she engages in less unhealthy behavior.

Which of the two channels matters more is an empirical question, which we tackle using three representative surveys. We find that individuals who overestimate their health are significantly more likely to not exercise, to eat unhealthy, to be overweight, and to sleep fewer hours. The statistical relationships are robust to correcting for socio-demographics, personality traits, cognitive skills, and risk aversion. They are also robust across our two notions of overconfidence. 


\section{Introduction}

Can risky health behavior be "optimal"? While most non-economists would immediately refute this thought, economists would probably answer "it depends" and refer to one of their workhorse models, the Rational Addiction Model (Becker and Murphy, 1988). Most economists fundamentally believe that rational forward looking agents would correctly assess the costs and benefits of their actions and then maximize their utility by consuming the optimal amount, such that the marginal costs equal the marginal benefits.

Behavioral economists have challenged this traditional view by empirically and theoretically studying behavior that deviates from rational forward-looking decision-making (cf. Rabin, 2013). In health economics, influential studies have shown that consumers pick dominated health plans and leave money on the table (e.g. Ketcham et al., 2012, 2016; Abaluck and Gruber, 2011, 2016; Bhargava et al., 2017). Handel and Kolstad (2015) show that consumers lack insurance-related information and incorporate such frictions into welfare models. Other papers have cited behavioral phenomena as explanations for why people engage in "too much" risky health behavior (c.f. Cawley and Ruhm, 2011). For example, theoretical papers model the role of hyperbolic discounting and time inconsistencies for smoking and overeating (Gruber and Kőszegi, 2001; Cutler et al., 2003; Strulik and Trimborn, 2018). In a seminal empirical paper, Della Vigna and Malmendier (2006) show that many gym members actually overpay as they exercise too little. They propose overconfidence about future self-control as one possible explanation for such observed behavior. To evaluate tools that nudge people to exercise regularly, follow-up studies have implemented field experiments. However, nudges appear to only be effective in the short-term (Royer et al., 2015; Carrera et al., 2018, 2020). ${ }^{1}$ This paper investigates the relationship between individual risky health behavior and health perception biases, about which only a small literature exists. ${ }^{2}$

As a first contribution, we formally introduce the concept of health perception biases into the (health) economics literature and document the existence of health perception biases in the population using three representative surveys. Specifically, we propose two individual mea-

\footnotetext{
${ }^{1}$ In one of the few lab experiments on this topic, Belot (2017) randomly updates students' beliefs about their likelihood to contract diseases in the next 10 years and then study the impact on dietary choices.

${ }^{2}$ A notable exception is Harris (2017) who finds that people who overestimate their activity levels consume more calories. In earlier studies, Cawley and Philipson (1999) use life insurance data and the differential between perceived and predicted mortality risk to show that observed empirical patterns are inconsistent with standard insurance theory under perfect information. A possible explanation is that insurance mandates make low risk individuals worse off if many market participants are overconfident (Sandroni and Squintani, 2007).
} 
sures, absolute and relative health perception biases, whose empirical measurement we borrow from the growing literature on overconfidence (c.f. Tiefenbeck et al., 2018; Friehe and Pannenberg, 2019). Absolute perception biases are biased perceptions of own health, whereas relative perception biases are biased perceptions relative to population health. We show that, under plausible assumptions, there exists a one-to-one positive mapping between the two health perception measures.

To measure absolute health perception biases, we use objectively diagnosed health conditions (here: high cholesterol and high blood pressure) and how respondents' perceptions about having such a condition deviate from the facts. In a representative German survey, we find that $30 \%$ of the population have biased perceptions about their high cholesterol levels. To measure relative health perception biases, specifically for this paper, we asked respondents to rank their health status relative to a reference group. The literature on overconfidence has used very similar survey measures. For the purpose of this paper, we included a health variant of this measures in two high-quality surveys from Germany (one representative survey and one interdisciplinary survey with rich measures on cognitive skills and risk aversion). Comparing the elicited subjective ranking to the objective ranking within the population health distribution (as measured by the SF12), produces our measure of relative health perception biases. Consistent with the absolute measure, we find that about $30 \%$ of the respondents overestimate their rank in the population health distribution by at least 30 ranks. That is, for instance, they believe that they rank at the $70^{\text {th }}$ percentile when they actually only rank at the $40^{\text {th }}$ percentile of the population health distribution. In particular, we find an excess mass of people who believe that they rank between the $70^{\text {th }}$ and the $90^{\text {th }}$ percentile of the population health distribution.

We acknowledge that our definition of health perception biases may have different meanings and implications in different fields of the social sciences. Moreover, different fieldseven subfields within the same discipline-have different empirical measures for phenomena such as overconfidence or overoptimism (cf. Camerer and Lovallo, 1999; Barber and Odean, 2001; Benoît and Dubra, 2011; Merkle and Weber, 2011; Burks et al., 2013; Spinnewijn, 2015; Bago d'Uva et al., 2017; Cowan, 2018). For example, Ortoleva and Snowberg (2015a) define overconfidence as the difference between respondents' estimated inflation and unemployment rates and the true rates, net of respondents' self-reported confidence about their estimates. Outside of economics, separate literatures on overoptimism biases (e.g. Weinstein, 1980, 1989; Sharot, 2011) and self-esteem (e.g. Himmler and Koenig, 2012) exist. In the literature on exper- 
imental methodology, Harrison et al. (2015); Di Girolamo et al. (2015) and Harrison et al. (2017) show how to correctly elicit subjective beliefs in lab experiments.

Regarding our definition of absolute health perception biases, there exists a related health economic literature on "reporting heterogeneity" or response errors in subjective health measures (Lindeboom and van Doorslaer, 2004; Jürges, 2007, 2008; Bago d'Uva et al., 2008; Ziebarth, 2010) as well as objective health measures (Baker et al., 2004; Davillas and Pudney, 2017; Choi and Cawley, 2018). Moreover, absolute health perception biases could be interpreted as "unawareness." Empirically, in the field, it is very challenging-if not impossible-to distinguish biased beliefs from reporting errors or unawareness. We entirely agree that such alternative labels and interpretations are feasible. As a consequence, we define perception biases broadly and deliberately allow for unawareness about one's health condition. Precisely for that reason, we elicit and compare measures of absolute and relative perception biases. Similarly, to bound the impact of reporting errors in subjective health, we benchmark our relative health perception measure against both the standard Self Assessed Health (SAH) measure and the 12-Item Short Form (SF12) health survey measure. By construction, the latter includes fewer systematic response biases. The empirical pattern and population distributions of two absolute and two relative bias measures across three different surveys yield important insights into the robustness and prevalence of such biases.

As a second main contribution, we provide a theoretical framework that shows how biased health perceptions can affect risky health behavior. The framework is simple and flexible enough to explain nonlinear patterns between biased beliefs and risky behavior. Moreover, it highlights that biased health perceptions affect behavior through an extensive and an intensive margin, and that these margins operate in opposite directions. When the extensive margin dominates, risky health behavior and biased health perceptions are complements. This means that, the higher the perception of own health, the more an individual engages in unhealthy behavior, such as consuming fast food or not exercising. This is akin to saying: "Because I believe I am very healthy and can afford it, I eat more fast food and exercise less." On the contrary, when the intensive margin of perceived health dominates, risky behavior and health biases are substitutes, hence a higher perceived health reduces risky behavior. This is akin to saying: "Because I perceive large health costs of risky behavior, I will eat less fast food and exercise more." Whether the extensive or intensive margin dominates is an empirical question which we tackle using three representative surveys. 
As a third contribution, we document a robust statistical link between health perception biases and risky health behaviors across all three surveys. Specifically, individuals who overestimate their health are significantly more likely to not exercise, to eat unhealthy, to be overweight and to sleep fewer hours. The statistical relationships are robust to controlling for sociodemographics, personality traits, cognitive skills, and risk aversion. They are also robust across our two notions of overconfidence. In the context of our model, these results are consistent with a dominant role of the extensive margin of health perception biases. Conversely, we do not find significant relationships for unbiased respondents and for those who are pessimistic about their health, a finding that is consistent with the extensive and intensive margin of health perception bias offsetting each other. ${ }^{3}$

Notably, smoking is not correlated with biased health perceptions. This result is consistent with Darden (2017), who finds that cardiovascular biomarker information at repeated health exams does not significantly alter smoking behavior. A possible explanation is that signals and information about own health, be it objective as in Darden (2017) or perceived as in this paper, are not powerful drivers of smoking behavior, possibly because its addictive nature prevents the proper evaluation of the health consequences of smoking.

Finally, we would like to point out that this paper remains agnostic about the sources of biased beliefs. The origins of these biased beliefs are still poorly understood. They have been linked to image motivation (Bénabou and Tirole, 2002) and humans' desire of being perceived positively by others (Burks et al., 2013; Goette et al., 2015; Charness et al., 2018), as opposed to managing a favorable self-image (Santos-Pinto and Sobel, 2005; Kőszegi, 2006; Weinberg, 2006) or self-serving biases (Babcock and Loewenstein, 1997; Di Tella et al., 2015). Explanations based on models with rational agents have been proposed (Benoît and Dubra, 2011), but have not always been corroborated by the empirical evidence (Merkle and Weber, 2011; Burks et al., 2013).

\section{Defining Health Biases}

In this section, we define absolute and relative health biases. In the empirical section, we will investigate those biases. Our definitions are consistent with the definition of overconfidence in

\footnotetext{
${ }^{3}$ As it is common in this literature, our results cannot exclude that health perception biases and risky health behaviors are linked via unobservables, for instance genes (Linnér et al., 2019), or that the causality runs from risky behaviors to perception biases in the form of self-serving biases (Bénabou and Tirole, 2002).
} 
the behavioral economics literature. Generally speaking, and outside the health domain, overconfidence implies that a person believes that her ability, performance or information is better than it actually is (Ortoleva and Snowberg, 2015b; Heidhues et al., 2019). Operationally, this notion has been measured in different ways, either as (i) overestimation of own performance, (ii) overplacement of own performance relative to others, or (iii) overprecision of own information (Moore and Healy, 2008). Our definition of absolute and relative health perception biases are akin to the first two measures, overestimation and overplacement.

Consider a risky health behavior $x_{i}$ which impairs individual health $H_{i}$ according to the health production function $H_{i}=g\left(x_{i}\right)$, with $g^{\prime}<0$ and $g^{\prime \prime}>0$. For each individual $i$, we define the individual perceived health status $\widetilde{H}_{i}$ as

$$
\widetilde{H}_{i} \equiv A_{i} H_{i}=A_{i} g\left(x_{i}\right)
$$

The term $A_{i}$ measures the individual's absolute health perception bias. If $A_{i}=1$, the individual has a correct perception of her own health $\left(\widetilde{H}_{i}=H_{i}\right)$, and a correct perception of the impact of her risky health behavior on health $\left(\widetilde{H}_{i}=g\left(x_{i}\right)\right)$. If $A_{i}>1$, individual $i$ displays absolute health overconfidence. This could be the case because she believes that her health is better than it really is, or because she believes that her risky health behavior is less health-damaging than it actually is. In either case, for a given health behavior, perceived health is better than true health. If instead $A<1$, we say that the individual displays absolute health underconfidence.

Next, given $H_{i}$, define the objective relative position (ranking) in the population health distribution as:

$$
r_{i} \equiv 100 \cdot F\left(H_{i}\right)
$$

where $F\left(H_{i}\right) \equiv \int_{0}^{H_{i}} d F(H)$ is the cumulative distribution function of population health (it is multiplied by 100 to provide a ranking on a $0-100$ scale, as in the survey question that elicits this measure). Analogously, let the subjective health ranking be

$$
\widetilde{r}_{i} \equiv 100 \cdot P_{i} F\left(\widetilde{H}_{i}\right)
$$


where $P_{i}$ is the bias in the perception of the cumulative distribution function of population health. If $P_{i}>1$, individual $i$ believes that there are more people in bad health than there actually are; this can also be interpreted as pessimism bias about population health.

The comparison between $r_{i}=r_{i}\left(H_{i}\right)$ and $\widetilde{r}_{i}=\widetilde{r}_{i}\left(P_{i}, A_{i} H_{i}\right)$ allows to identify the drivers of health biases. Both rankings depend on risky health behavior and objective health. However, the subjective ranking $\widetilde{r}_{i}$, also depends on the absolute health perception bias $A_{i}$, and the perception of the population health distribution $P_{i}$.

Remark 1 For a given reference population:

- The objective health ranking $r_{i}$ decreases with risky health behavior and increases with better objective health: $\frac{\partial r_{i}}{\partial x_{i}}<0, \frac{\partial r_{i}}{\partial H_{i}}>0$

- The subjective health ranking $\widetilde{r}_{i}$ decreases with risky health behavior and increases with better objective health, the absolute health perception bias and the population health pessimism bias: $\frac{\partial \widetilde{r}_{i}}{\partial x_{i}}<0, \frac{\partial \widetilde{r}_{i}}{\partial H_{i}}, \frac{\partial \widetilde{r}_{i}}{\partial A_{i}}, \frac{\partial \widetilde{r}_{i}}{\partial P_{i}}>0$.

For each individual $i$, we define the relative health perception bias $R_{i}$ as the difference between the subjective and the objective ranking in the population health distribution:

$$
R_{i}=\widetilde{r}_{i}-r_{i}
$$

We say that individual $i$ displays relative health overconfidence when $R_{i}>0$, and that she displays relative health underconfidence when $R_{i}<0$. Manipulating equation (4) allows us to decompose the relative health bias into two components:

$$
\begin{aligned}
R_{i} & =100\left[P_{i} F\left(A_{i} H_{i}\right)-F\left(H_{i}\right)\right] \\
& =100\left[F\left(A_{i} H_{i}\right)-F\left(H_{i}\right)\right]+100\left(P_{i}-1\right) F\left(A_{i} H_{i}\right)
\end{aligned}
$$

The first component of equation (6) depends on the absolute health bias $A_{i}$ : it is equal to zero if $A_{i}=1$, and it increases as $A_{i}$ increases. The second component is equal to zero if the perception of the population health distribution is correct $\left(P_{i}=1\right)$, and it increases as $P_{i}$ increases.

Based on equation (5), we can state the following 
Remark 2 For a given reference population and for a given belief $P_{i}$ about population health, there exists a one-to-one positive correlation between the absolute and the relative health bias.

The above remark emphasizes a convenient property that allows us to use the relative health perception bias $R_{i}$ as a proxy for the absolute health perception bias $A_{i}$. This assumption is not particularly restrictive if the perceived ranking $\widetilde{r}_{i}$ is not very sensitive to the specific shape of the population health distribution.

\section{Model}

To investigate the role of perceived health for health behavior, consider an individual that derives utility from risky health behavior $x$, perceived health $\widetilde{H}=A H=A g(x)$, and consumption of a numeraire good $q$. To fix ideas, consider the following utility function

$$
U(x, \widetilde{H}, q)=B(x)+\mathcal{H}(\widetilde{H})+q
$$

The first term $B(x)$ is the utility of a risky health behavior such as smoking, overeating, not exercising or not sleeping enough. The second term $\mathcal{H}(\widetilde{H})$ describes the benefits of perceived health. It can include mental and physical health, as well as any motive that links perceived health to, e.g., social image concerns, peer pressure, conformism to social norms or self-esteem. We assume that both, the utility of risky health behavior and the utility of health, are increasing and concave.

Given income $M$ and prices $p$, the individual chooses risky behavior $x$ by maximizing (7) subject to $M=p x+q$ and $\widetilde{H}=A g(x)$, with $x \in[0, M / p]$. Replacing the constraints in the objective function, this is equivalent to solving

$$
\max _{x} B(x)+\mathcal{H}(A g(x))+M-p x
$$

The optimal amount of risky behavior $x^{*}$ satisfies the following first order condition:

$$
x^{*}: \quad B^{\prime}(x)-p+A \mathcal{H}^{\prime}(A g(x)) g^{\prime}(x)=0
$$


Equation (9) implies that optimal risky behavior trades-off the marginal benefits $B^{\prime}>0$ of risky behavior, its price $p$, and its marginal impact on perceived health $A \mathcal{H}^{\prime} g^{\prime}<0$. The latter term has a negative sign because more risky behavior reduces health $\left(g^{\prime}<0\right)$, with a magnitude that depends on the absolute health perception bias $A$. In fact, the absolute health bias $A$ plays a double role for optimal risky behavior. First, it affects perceived health $(\widetilde{H}=A g(x))$ in the marginal perceived health function $\mathcal{H}^{\prime}(\cdot)$. Because changes in $A$ affect perceived health at the margin, that is, the "last unit" of perceived health, we will call it the extensive margin of perceived health. Second, $A$ affects the magnitude of the marginal cost of risky behavior, $\mathcal{H}^{\prime} g^{\prime}$. Because this channel determines the impact of $A$ for all "inframarginal units" of risky behavior, we will call it the intensive margin of perceived health.

Ultimately, we want to assess how an increase in the health perception bias $A$ (or its proxy $R$, as per Remark 2) affects risky health behavior. This amounts to studying, omitting the arguments,

$$
\frac{d x^{*}}{d A}=\frac{-g^{\prime}}{U^{\prime \prime}}\left(\widetilde{H} \mathcal{H}^{\prime \prime}+\mathcal{H}^{\prime}\right)
$$

The first and the second term in brackets refer to the extensive and the intensive margin of perceived health, respectively. Since $-g^{\prime} / U^{\prime \prime}<0$, the extensive margin implies a positive effect of the health perception bias on optimal risky behavior. To give an example, the effect on the extensive margin is akin to saying "Because (I think) I am healthy enough to not exercise, I decide to not exercise." In contrast, the intensive margin implies a negative effect of the health perception bias on optimal risky behavior. It is akin to saying "Because I don't want to jeopardize my (perceived) high health status, I will exercise more."

Based on equation (10) the following holds:

Remark 3 Optimal risky behavior increases if the effect of the absolute health bias on perceived health is larger than the effect on the marginal cost of risky behavior, and it decreases otherwise.

The above remark shows that the balance between the extensive margin and the intensive margin of perceived health determines whether optimal risky health behavior ultimately increases or decreases with health perception biases. Recall that the extensive margin refers to the effect of perceived health on risky behavior: since the agent thinks she is very healthy, she believes she can afford engaging in risky behavior. Accordingly, the better the perceived 
health, the more risky behavior, which implies they they are complements. The intensive margin, instead, implies that the absolute health bias increases the marginal cost of risky behavior. Accordingly, the agent reduces risky behavior the more she has a health bias, which implies that they are substitutes. Overall, when the health perception motive dominates the cost of risky behavior (i.e. when the extensive margin dominates), more health overconfidence results in more risky behavior.

Equation (10) and the remark can alternatively be described in terms of relative risk aversion. Define $\sigma \equiv-\widetilde{H} \mathcal{H}^{\prime \prime} / \mathcal{H}^{\prime}>0$ as the coefficient of relative risk aversion of perceived health, denote $\alpha \equiv \mathcal{H}^{\prime} g^{\prime} / U^{\prime \prime}>0$, and replace in (10) to obtain $d x^{*} / d A=\alpha(\sigma-1)$. Hence the sign of $d x^{*} / d A$ depends on whether the relative risk aversion of perceived health is larger or smaller than one. In the special case of a CRRA perceived health function, $\mathcal{H}(\widetilde{H})=\frac{1}{1-\sigma} \widetilde{H}^{1-\sigma}$, the coefficient of relative risk aversion $\sigma$ is constant and independent of perceived health. Accordingly, risky behavior monotonically increases with the health perception biases if $\sigma>1$, and it monotonically decreases if $\sigma<1$. If instead $\sigma=1$, the effect of $A$ on $x^{*}$ is nil. In general, however, the effect can be non-monotonic. For example, if the health function is quadratic or exponential, the relation between health perception biases and health behavior is U-shaped. ${ }^{4}$

\section{Datasets}

To empirically identify the relationship between health perception biases and risky health behavior, we exploit three representative German surveys. The first survey is the German National Health Survey East-West 1991 (GNHSEW91s), which is representative of the German population. The GNHSEW includes objective health measures, taken by health care professionals. By comparing specific clinical diagnoses of high cholesterol and high blood pressure to respondents' perceptions about such conditions, we generate measures of absolute health perception biases.

The second survey is the Berlin Aging Study II (BASE-II), which is representative of elderly residents in Berlin. This dataset includes objective health measures, taken by health care professionals, cognitive tests and rich socio-demographic background information. The BASE-II

\footnotetext{
${ }^{4}$ For simplicity, in this example $A$ does not affect the utility of risky health behavior. In the more general case $U(x, \widetilde{H})+q$ where risky behavior and perceived health are non-separable, the sign of $d x^{*} / d A$ depends on whether the marginal utility of perceived health $U_{\widetilde{H}}$ is large enough, as in the separable case. Specifically: $d x^{*} / d A>0$ if and only if $U_{\widetilde{H}}>-\widetilde{H} U_{\widetilde{H} \widetilde{H}}-g U_{\widetilde{H} x} / g^{\prime}$
} 
also contains subjective health measures and the SF12. Most importantly, for this paper, we added a question to BASE-II that elicits respondents' perceived rank $\widetilde{r_{i}}$ in the population health distribution.

The third survey is the Innovation Panel of the representative German Socio-Economic Panel Study (SOEP-IP). The SOEP-IP includes the standard socio-demographics of the SOEP, self-reported health measures as well as the SF12. In addition to adding it to BASE-II, we also included the same measure on respondents' perceived rank in the population health distribution to SOEP-IP. Hence we can measure perceived ranking $\widetilde{r_{i}}$ and, together with the objective ranking $r_{i}$ from the SF12, generate measures of relative health perception biases, $R_{i}$.

\subsection{German National Health Survey East-West 1991 (GNHSEW91)}

The GNHSEW91 is a representative cross-sectional survey of the German population. It was in the field in East and West Germany between 1990 and 1992 (Robert Koch Institut, 2012). Many questions are nutrition and health-related; our GNHSEW91 working sample consists of 6,429 respondents. Importantly, health care professionals measured both, the clinical blood pressure as well as the cholesterol levels of all respondents (Panel B of Table A1, Appendix). In addition, GNHSEW91 surveys respondents' perceptions about whether they have high blood pressure or high cholesterol levels (Panel C of Table A1). Comparing perceived $\left(\widetilde{H}_{i}\right)$ and true health $\left(H_{i}\right)$ allows us to measure absolute health perception biases (Panel A of Table A1 and Section 5.1).

Health Behavior. Panel D of Table A1 (Appendix) lists measures of risky health behaviors. Thirty-three percent are current smokers and 49\% do not exercise at all (No sports). Thirteen percent consume alcohol daily and the average BMI is 26.6 .

\subsection{Berlin Aging Study II (BASE-II)}

The BASE-II consists of several parts: The first part is the Socio-Economic Module that comprises standard questions of the Socio-Economic Panel Study (SOEP) (Wagner et al., 2007). This

part includes self-reported socio-demographics, health and health behavior measures (Böckenhoff et al., 2013).

The second part is the Clinical Module. It includes clinical health measures, taken in the Charité University Hospital of Berlin. (Additional parts include cognitive and other tests which 
were administered by psychologists but which are not the focus of this paper. ${ }^{5}$ ) The BASEII is representative of the elderly Berlin population up to age 89. As a supplement, BASEII also surveys a sample of younger Berlin residents aged 18 and above; the ratio between respondents above and below 60 is 3:1 (see Appendix, Table A2). Bertram et al. (2014) provide more information on the BASE-II. Our working sample consists of 1,780 respondents without missings on relevant variables.

For this paper, we included a measure to elicit $\widetilde{r_{i}}$ in the Socio-Economic Module of BASE-II, which was in the field between September and December 2012. Section 5.2 discusses the health bias measures in detail, also see Panel A of Table A2.

Health Behavior. Panel B of Table A2 lists measures of risky health behavior: smoker, no sports, unhealthy diet, obese and BMI. As seen, 12\% smoke, 36\% do not exercise, 39\% have an unhealthy diet, and $13 \%$ are obese.

Socio-Demographics. Panel C of Table A2 lists socio-demographic variables. There are five main categories: (i) Demographics, (ii) Education, (iii) Employment, (iv) Behavioral Attitudes, and ( $v$ ) Big Five. The average age of BASE-II respondents is 60; slightly more than half of them are female and married; a quarter are single. Fifty-six percent of the sample finished high school (13 school years) and almost half are still full-time employed. In our regression models, we also control for risk aversion and trust, which are important covariates when eliciting subjective beliefs (e.g. Harrison et al., 2015, 2017). Accordingly, 15\% of BASE-II respondents are risk loving (highest three categories of the standard 0 to 10 Likert risk aversion scale, see Dohmen et al., 2011). Almost forty percent say that they have "a lot of" or "quite some" trust in strangers. Finally, we also control for the Big-Five. The five dimensions are simple averages over three or four subscales which range from one to seven (Richter et al., 2013). Conscientiousness has the highest average of 5.6 and Agreeableness the lowest with 3.8 (Panel C, Table A2).

\subsection{Socio-Economic Panel Study - Innovation Panel (SOEP-IP)}

Since 2012, the SOEP has been inviting researchers to submit proposals for innovative survey questions (Richter and Schupp, 2015). Proposals are then reviewed by an expert committee. If accepted, the proposed questions become part of SOEP-IP, which is in the field annually from September to December. SOEP-IP respondents also answer the regular SOEP core questions

\footnotetext{
${ }^{5}$ Our findings are robust to controlling for cognitive measures. Detailed results are available upon request.
} 
(Richter and Schupp, 2017). In 2014, a total of 1,377 respondents answered the same health perception measure, $\widetilde{r}$, that we also included in BASE-II. Comparing relative health perceptions to true health allows us to construct relative health perception bias measures $R_{i}$ (see Panel $\mathrm{A}$ of Table A3 and Section 5.2).

Health Behavior. In 2014, the SOEP-IP did not ask about smoking, exercising, and respondents' diet. However, the SOEP-IP elicited the average hours of sleep (Richter and Schupp, 2015). On average, Germans sleep 6.8 hours during the week and 7.6 hours on weekends (Panel B of Table A3). We use these information to generate sleep gap measures that indicate the difference to eight hours of sleep.

Socio-Demographics. As above, Panel C of Table A3 lists socio-demographics. Because BASE-II and SOEP-IP both include SOEP's socio-demographic core questions, we generate almost identical socio-demographic control variables. By design, representative SOEP-IP respondents are younger (51 vs. 60 years) but the shares of female and married respondents are very similar, slightly above fifty percent. In SOEP-IP, two thirds are full-time employed and the average monthly net income is $€ 1,773$.

\section{Measuring Health Perception Biases}

This section shows how we operationalize health perception biases using survey data.

\subsection{Measuring Absolute Health Perception Biases}

To measure absolute health perception biases, we use the German National Health Survey EastWest 1991 (GNHSEW91). This dataset contains information on individual blood pressure and cholesterol levels, collected by the Institute for Prevention and Public Health in Berlin, Germany. We use these measures as proxies for the individual objective health status $H_{i}$. We dichotomize these continuous objective measures depending on whether they are above or below the medically defined threshold to indicate specific clinical conditions. Specifically, for blood pressure, we define that a respondent has high blood pressure, and $B P_{i}$ equals one, if the systolic value is larger than $160 \mathrm{mmHg}$ and/or the diastolic value exceeds $95 \mathrm{mmHg} ; B P_{i}$ equals zero otherwise. Analogously, for high cholesterol levels, we define a dummy $\mathrm{Chol}_{i}$ equal to one for values larger than $6.2 \mathrm{mmol} / 1$, and zero otherwise. Because GNHSEW91 also elicits 
perceptions about these conditions, we then compare these objective clinical outcomes $B P_{i}$ and Chol $_{i}$ with respondents' perceived high blood pressure, $\widetilde{B P}_{i}$, and high cholesterol levels, $\widetilde{C h o l}_{i}$, to obtain an assessment of absolute health overconfidence. Each surveyed individual provides self-assessed binary measures of $\widetilde{B P}$ and $\widetilde{C h o l}_{i}{ }^{6}$

Panel B of Table A1 (Appendix) shows a mean cholesterol level of 6.1 millimole per liter $(\mathrm{mmol} / \mathrm{l})$ and that $44 \%$ of all Germans have high cholesterol levels $\left(B P_{i}=1\right)$. Panel B of Table A1 also shows mean systolic blood pressure levels of 135 millimetres of mercury ( $\mathrm{mmHg}$ ) and mean diastolic blood pressure levels of $83 \mathrm{mmHg} .{ }^{7}$ Following the official WHO definition at the time, $21 \%$ of Germans had hypertension $\left(\mathrm{Chol}_{i}=1\right) .{ }^{8}$ Panel $\mathrm{C}$ shows that $21 \%$ of respondents knew that they suffered of hypertension $\left(\widetilde{B P_{i}}=1\right)$ and that $25 \%$ knew that they had high cholesterol $\left(\widetilde{\mathrm{Chol}}_{i}=1\right)$.

\section{[Insert Figure 1 about here]}

As good health corresponds to $B P_{i}=0$ or $C h o l_{i}=0$, absolute overconfidence results if $\widetilde{B P_{i}}<B P_{i}$ or $\widetilde{C h o l}_{i}<C_{h o l}$. Figure 1a illustrates the four possible combinations of the binary measures of objective and perceived health for cholesterol. Individuals in the bottom-right corner display absolute overconfidence. This corresponds to $30 \%$ of respondent who actually have high cholesterol levels, but are not aware of it. The bottom-left corner shows that $50 \%$ of all respondents do not have high cholesterol levels, and consistently report that they do not have high cholesterol. As shown in the top-right corner, $14 \%$ correctly state that they have high blood cholesterol levels. ${ }^{9}$

Figure $1 \mathrm{~b}$ has the same setup and shows the analogous distribution for high blood pressure. Accordingly, $66 \%$ of all respondents correctly state that they do not have high blood pressure (bottom-left corner), and 12\% correctly state that they do have high blood pressure (top-right corner). Nine percent indicate that they never had high blood pressure although the clini-

\footnotetext{
${ }^{6}$ Note that there is a small literature on misreporting of clinical diagnoses (Baker et al., 2004; Davillas and Pudney, 2017; Choi and Cawley, 2018). It is distinct from the literature on overconfidence. It is certainly up to scientific debate on how to define this phenomenon. People are either unaware and have biased health perceptions (our interpretation) or they are aware of their health condition but deliberately misreport it, for example, due to a desirability bias.

${ }^{7}$ Each measure was taken three times from each respondent; we use data from the second measure.

${ }^{8}$ In the meantime, the official definitions have been downgraded. In November 2017, the American Heart Association and the American College of Cardiology redefined the thresholds to 130/80 (American Heart Association, 2017).

${ }^{9}$ We ignore the $6.5 \%$ in the top-left corner who had no high cholesterol at the time of the survey, but who claim that they had been diagnosed before (as the statement may or may not be true).
} 
cal measures show the opposite (bottom-right corner). ${ }^{10}$ The smaller perception bias for high blood pressure as compared to high cholesterol is consistent with the notion that it is easier to check for high blood pressure than high cholesterol levels outside of clinical settings.

\subsection{Measuring Relative Health Perception Biases $R_{i}$}

To measure relative health perception biases $R_{i}=\widetilde{r}_{i}-r_{i}$, we make use of the BASE-II and the SOEP-IP.

To measure $H_{i}$ (which is needed to construct $r_{i}$ ), both the BASE-II and the SOEP-IP contain the standard SAH measure as well as the SF12 measure. Both measures have been routinely used by health economists and public health scientists. SAH asks about the overall health status; respondents self-categorize as being in excellent, very good, good, fair, or poor health. However, although widely available and easy to collect, the literature has documented systematic SAH response biases with respect to age and gender (Lindeboom and van Doorslaer, 2004; Jürges, 2008; Bago d'Uva et al., 2008; Ziebarth, 2010; Spitzer and Weber, 2019), which we control for in our setting.

To minimize concerns about reporting biases, we employ the generic and continuous SF12 as an alternative $H_{i}$ measure (Andersen et al., 2007). The SF12 belongs to the "health-related quality of life measures." Using a specific algorithm, the SF12 weights and aggregates the answers to twelve health questions into a physical health (pcs) and a mental health (mcs) summary scale. Compared to SAH, the SF12 is a "more" objective health measure and was developed to minimize reporting biases. It "can be used to compare the health of different groups, for example, the young and the old or the sick and the well" (RAND, 1995). Both subscales of the SF12, pcs and mcs, have continuous values between 0 and 100, mean 50, and a standard deviation of 10 . We use equal weights of 0.5 to generate the overall continuous SF12 measure.

Figures A1 and Figure A2 in the Appendix show the distributions of SAH and SF12 in our BASE-II (Figure A1) and SOEP-IP sample (Figure A2). The left panels refer to SAH and the right panels refer to SF12. The health distributions appear very similar, both across measures and across databases.

The SAH and SF12 allow us to infer $H_{i}$ as well as the population health distribution $F\left(H_{i}\right)$. Hence it is straightforward to calculate the individual rank $r_{i}$ in the health distribution. For

\footnotetext{
${ }^{10}$ Note that the prevalence of the medical condition also determines the prevalence of absolute overconfidence. However, correcting responses by the prevalence rate is outside the scope of this paper.
} 
$\mathrm{SAH}$, each respondent self-categorizes into one of the five SAH categories. Then, we assign every respondent the upper cdf threshold of the category chosen in the SAH distribution. For example, $9 \%$ of all respondents self-categorize to be in the highest category "excellent" health. Hence we assign $r_{i, S A H}=91$ to all respondents in the second highest category "very good" and, using the same principle, we do the same for the other categories. Because SF12 is continuous, ranges from 0 to 100 and has mean 50, it directly yields $r_{i}$ without further manipulation.

To measure $\widetilde{r_{i}}$, we added the following question to BASE-II and SOEP-IP: "Imagine one would randomly select 100 people in your age, what do you think: How many of those 100 people would be in better health than you?".11 From the raw untransformed response to this question, $\widetilde{b_{i}}$, we compute $\widetilde{r_{i}}=100-\widetilde{b_{i}}$.

In both surveys, we obtain a high response rates of above $90 \%$ for our $\widetilde{b_{i}}$ measure. Even among the elderly in BASE-II, only 10 respondents $(<1 \%)$ are coded "don't know" and 129 respondents $(6 \%)$ are coded "does not apply." The high response rates may be a function of the natural reference group-100 people in the same age group. This framing allows meaningful comparisons without being too restrictive or too complex. Note that, despite avoiding many of the methodological criticisms of earlier studies (Benoit and Dubra, 2011), our question does not elicit entire belief distributions (Di Girolamo et al., 2015). Moreover, we did not specifically incentivize respondents (Harrison and Rutström, 2006). Eliciting entire belief distributions in an incentive-compatible environment is typically feasible in lab experiments (Harrison, 2015), which is costly and can only be implemented in large samples under specific conditions. In addition to the advantages above, maybe the main advantage of our measure of $\widetilde{b_{i}}$ is its simplicity and cost-effectiveness. Using one simple question, our proposed question has the power to elicit subjective relative beliefs in representative population surveys.

\section{[Insert Figure 2 about here]}

Figure 2 shows the raw untransformed distributions of $\widetilde{b_{i}}$ for BASE-II and SOEP-IP. Under the assumption of 100 random people being orderly ranked from 1 to 100 and under full rationality and common priors, $\widetilde{b_{i}}$ would be uniformly distributed between 0 and 100 with a mean of 50 (Goette et al., 2015). However, as seen in Figure 2, few respondents say that more than 50 respondents in their age would be in better health and the distribution is clearly skewed to the

\footnotetext{
${ }^{11}$ This survey question has been successfully tested in other contexts. For example, using the same format, respondents in the Swiss "Amphiro" study were asked about their income position, their water use, and their knowledge of energy conservation (Tiefenbeck et al., 2018; Friehe and Pannenberg, 2019).
} 
left. It is worthwhile to emphasize the similarity of the $\widetilde{b_{i}}$ distributions in BASE-II and SOEPIP; the mass of the distributions lies between 10 and 30. In other words, a significant share of respondents believe that (only) 10-30 out of 100 people are in better health $\left(\widetilde{b_{i}} \in(10 ; 30)\right)$ implying that they rank themselves in the $70^{\text {th }}$ to $90^{\text {th }}$ percentile of the population health distribution, $\widetilde{r_{i}} \in(70 ; 90)$. This yields first evidence for the existence of relative health perception biases at the population level.

\section{[Insert Figure 3 about here]}

More evidence for the existence of relative health perception biases is illustrated by Figure 3 , which plots the bins of $\widetilde{r_{i}}$ on the x-axis and the average values for $r_{i}$ on the y-axis. The scatters, whose size indicate the share of respondents falling into each bin, would be lined up along the 45-degree line if $\widetilde{r_{i}}=r_{i}$. However, as seen, while the scattered line has a slightly positive slope, it is clearly flatter than the 45-degree line.

Using $r_{i}$ and $\widetilde{r}_{i}$, we can now calculate $R_{i}$ for each respondent in BASE-II and SOEP-IP. Because BASE-II is representative of the elderly Berlin population, whereas SOEP-IP is representative of the entire German population, comparing the results of both surveys will inform us about the generalizability of the empirical findings. Calculating $R_{i, S F 12}=\widetilde{r}_{i}-r_{i, S F 12}$ is straightforward because both the SF12 and $\widetilde{r}_{i}$ are continuous. When calculating $R_{i, S A H}=\widetilde{r}_{i}-r_{i, S A H}$, recall that $\widetilde{r_{i}}$ is continuous, but $\mathrm{SAH}$ has five categories. However, because $\widetilde{r}_{i}$ is continuous and varies within $\mathrm{SAH}$ categories, $R_{i, S A H}$ is continuous as well, as shown by Figures 4 a (SOEP-IP) and A3a (BASE-II). Both figures also demonstrate that $R_{i, S A H}$ looks very similar in BASE-II and SOEP-IP and that the gender differences are negligible.

\section{[Insert Figure 4 about here]}

Figures $4 \mathrm{~b}$ (SOEP-IP) and A3b (BASE-II) show the distributions of $R_{i, S F 12}$. As seen in Panels A of Tables A2 and A3, the mean $R_{i, S F 12}$ values are 14 (SOEP-IP) and 20 (BASE-II), that is, clearly positive and implying that respondents overestimate their rank on average by 14 and 20 positions. Conditional on being overconfident, respondents overestimate their health rank by 23 (BASE-II) and 19 (SOEP-IP) positions. Again, the $R_{i, S F 12}$ distributions are very similar for BASE-II and SOEP-IP.

When studying determinants of $R_{i, S F 12}$ (details available upon request), one finds that the bias decreases in age and with the number of siblings. Moreover, it is highly correlated with 
education and decreases in the number of school years. Similarly, blue collar workers and lower-income respondents tend to be more biased, as are people with a lower self-reported trust level. Interestingly, $R_{i, S F 12}$ is not significantly correlated with the risk tolerance, being religious or the nationality.

\section{Health Perception Biases and Risky Health Behaviors}

In this section, we first study the empirical link between absolute health perception biases and risky health behavior using the GNHSEW91. Then we study the link between relative health perception biases and risky health behavior using the BASE-II and SOEP-IP. We will provide non-parametric evidence and evidence from multivariate regression models.

\subsection{Absolute Health Perception Biases and Risky Health Behavior}

Figure 5 tests whether respondents who have biased perceptions about their blood cholesterol levels are more likely to (a) not exercise, (b) have higher BMIs, (c) drink alcohol daily, (d) smoke. Figure 6 tests the same relationships for respondents who have biased perceptions about their blood pressure levels, see Section 5 for details about how we generated the perception bias measures. Each of the figures shows four bar diagrams along with 95\% confidence intervals.

\section{[Insert Figures 5 and 6 about here]}

Figure 5a shows that respondents who state that they do not have high cholesterol but who, in fact, do have high cholesterol are a highly significant 11 percentage points more likely ( $43 \%$ vs. $54 \%$ ) to not exercise at all. The BMI differential is also significant (Figure 5b). Similarly, respondents with absolute health perception biases are significantly more likely to drink alcohol daily-the share of daily drinkers is almost $50 \%$ higher among this group ( $21 \%$ vs. $14 \%$, Figure 5c). Figure $6 \mathrm{~d}$, however, does not provide much evidence that smoking is significantly linked to biased perceptions about high cholesterol levels.

Comparing Figure 6 to Figure 5, the similarity and robustness of the link between both absolute health perception bias measures and four risky health behavior measures is worthwhile to point out. Not only do all statistical links have identical signs and significance levels, but the risky behavior differentials and their sizes are also very similar. This is even more surprising, given the low correlation between the two perception bias measures of only 0.11 . 
In conclusion, there is robust evidence that absolute health perception biases ("health overconfidence") are significantly linked to three out of four risky behaviors. According to Proposition 3, this implies that the extensive margin effect dominates the intensive margin effect meaning that overconfident people engage in more unhealthy behavior because they (wrongly) believe that they can "afford" it. One exception appears to be smoking, where the effect on the intensive margin appears to be stronger. This intensive margin effect reduces the inclination to engage in risky behavior because the bias increases the marginal costs of risky behavior, see Section 3 for more details.

\subsection{Relative Health Perception Biases and Risky Health Behavior}

Figure 7 non-parametrically links $R$ to $x$ across the entire $R$ distribution using kernel-weighted local polynomial smoothing plots. Table 1 provides the equivalent parametric multivariate regressions using a rich set of controls.

\section{[Insert Figure 7 about here]}

No physical exercise. Figure 7a shows a monotonically increasing relationship between relative health overconfidence, $R>0$, and not exercising. On average, 30\% of those who accurately assess, or who underestimate their health, do not exercise at all. This share monotonically increases to $50 \%$ for respondents who overestimate their rank in the population distribution by 50 , that is, who exhibit strong health overconfidence.

Next, we run the following parametric regression model controlling for a rich set of sociodemographics:

$$
x_{i}=\beta_{0}+\beta_{1} R_{i}^{+}+\beta_{2} R_{i}^{-}+Z_{i} \beta_{3}+\rho_{t}+\epsilon_{i}
$$

where $x_{i}$ represents risky health behavior and $R_{i}$ stands for our relative health bias measure. Specifically, we will replace the continuous $R_{i}$ measure with two measures $R_{i}^{+}\left\{R_{i} \mid R_{i} \in\right.$ $(0 ; 100)$ and $R_{i}^{-}\left\{R_{i} \mid R_{i} \in(-100 ; 0) . R_{i}^{+}\right.$is truncated from below and measures the degree of health overconfidence. $R_{i}^{-}$is truncated from above and measures the degree of health underconfidence. 
$Z_{i}$ contains socio-demographic controls as listed in Table A2. Note that we also control for risk aversion, trust, and cognitive abilities. We also include interview month fixed effects, $\rho_{t} ; \epsilon_{i}$ is the error term.

\section{[Insert Table 1 about here]}

Table 1 shows the results of four regression models as in equation (11). The models in columns (1) and (3) do not control for personality traits and behavioral attributes (such as trust, measures or risk aversion or cognitive abilities), whereas the models in columns (2) and (4) do. The first two columns use $R_{i}$ measures based on the SF12 benchmark, and the last two columns use $R_{i}$ measures based on the SAH benchmark (Section 5).

Broadly speaking, the results from the four models confirm the non-parametric findings in Figure 7: there is no evidence that a negative health bias is significantly linked to not exercising. By contrast, similar to the evidence for absolute health overconfidence in Figures $5 \mathrm{a}$ and $6 \mathrm{a}$, we find a highly significant link between $R_{i}>0$ and not exercising: an increase in $R_{i}$ by 10 ranks is associated with a 1.5ppt higher likelihood to not exercise (column (2)). The size of the association is larger when using $R_{S A H}$ (columns (3) and (4)) but overall robust across columns.

\section{[Insert Tables 2 and 3 about here]}

BMI, Obesity and Unhealthy Diet. Figure $7 \mathrm{~b}$ and Table 2 show the equivalent findings for BMI, while Figure 7c and Table 3 show the findings for having an unhealthy diet. Both figures and tables reinforce our previous findings.

Figure $7 \mathrm{~b}$ shows a non-linear relationship between $R_{i}>0$ and BMI which is very similar to Figure 7a: Respondents who accurately assess their health or who underestimate their health do not have higher BMIs. However, the average BMI increases monotonically in the size of the health bias for $R_{i}>0$. In other words, the more people overestimate their health, the heavier they are. To test this link parametrically, we generate a binary obesity indicator as dependent variable $^{12}$ and run regressions similar to equation (11). The results in Table 2 confirm the nonparametric visual evidence: An increase in the health bias $R_{i}$ by 10 ranks is associated with a 1.5 percentage point (about 12\%) higher probability to be obese in the first two columns; it is associated with a 2.6 percentage point higher probability in the last two columns. As above,

\footnotetext{
${ }^{12}$ Using the continuous BMI measure yields robust results.
} 
the effect size is larger for $R_{S A H}$ but generally robust. The inclusion of rich sets of individual covariates, such as detailed measures of cognitive skills, do not matter for the strength of the empirical relationship.

Figure $7 \mathrm{c}$ and Table 3 corroborate the findings above. Whereas no link exists for respondents with $R_{i} \leq 0$, that is, unbiased or underconfident people, we find a clear and positive statistical link between being overconfident about one's health and unhealthy eating. An increase in the bias by 10 ranks increases the likelihood of an unhealthy diet by almost 2 percentage points (or about $4.5 \%$ ). This estimate is very robust across the health bias definitions and all four columns.

\section{[Insert Table 4 about here]}

Smoking. Figure $7 \mathrm{~d}$ and Table 4 show the results for being a smoker. The graphical evidence provides no evidence for a statistical link between health perception biases and smoking status. This is confirmed by the parametric regressions in Table 4-none of the eight health bias measures is significantly linked to smoking status and the effect sizes are very small. It is worthwhile to emphasize that this finding is exactly in line with the findings from above in Figures 5 and 6, where we found no association between absolute health overconfidence and smoking. According to our model, this implies that the health perception biases operate through a strong intensive margin effect, which emphasizes the costs of smoking (Section 3). This finding is consistent with Darden (2017), who reports that updated (and objective) cardiovascular biomarker information has not altered smoking behavior in the population of the Framingham Heart Study-Offspring Cohort.

\section{[Insert Figure 8 and Table 5 about here]}

Sleep. Finally, we use the representative SOEP to investigate the empirical relationship between relative health perception biases and sleep. Our outcome measures indicate the "sleep gap" between the actual hours of sleep and eight hours. Figure 8a shows again the characteristic pattern from above. The sleep gap is monotonically increasing in the size of the health bias-but only for $R_{i}>0$, that is, for overconfident people. For the underconfident and those who do not exhibit biases, no clear association between $R_{i}$ and $h_{i}$ exists. This holds for sleep during the week (Figure 8a) as well as sleep on weekends (Figure 8b).

Table 5 shows the results of regression models as in equation (11), using the sleep gap during the week as dependent variable (results for the weekend are similar and available upon 
request). We find a robust and clear link between a positive health perception bias and the likelihood to sleep fewer hours. The findings in the first two columns even suggest that the association could be linear and carry over for underconfident people, but with reversed signs, that is, the underconfident may sleep significantly more than those who correctly assess their health, implying that the intensive margin and thus the marginal costs of not sleeping enough dominates here and underconfident people do not want to jeopardize their health through a lack of sleep (Section 3).

Finally, in addition to the various discussed possibilities to interpret empirical measures of overconfidence and the challenge to induce clean exogenous variation, there exists another structural empirical challenge in the overconfidence literature: "ceiling effects." Specifically, it means that, from a statistical standpoint, the higher the actual skill level $r_{i}$, the lower the probability that someone is overconfident, by definition. Table 6 shows a robustness check that trims the relative health perception bias distribution and eliminates the top and bottom quintile of $R_{i} \cdot{ }^{13}$ Otherwise the model is the same as in equation (11). The column headers of Table 6 show the dependent variables; the models in the uneven columns do not control for education, personality traits and behavioral attributes, whereas the models in the even columns do. The result of the eight models corroborate our findings above: While there is no evidence that the likelihood to smoke increases or decreases in the bias, the likelihood to engage in risky health behavior increases in the bias for the other health behavior measures.

To summarize our empirical findings: First, except for the case of smoking, we find stable and statistically significant links between health overconfidence and risky health behavior. Second, no such link exists for respondents without bias or who exhibit a negative health perception bias, that is, those who are underconfident. Third, the findings are robust with respect to two self-reported general health measures as well as two very specific objective physical health measures. Fourth, the findings are also robust for the health behaviors exercising, eating, drinking and sleeping. Fifth, the empirical findings are consistent for both absolute and relative health perception biases. Lastly, interpreted in the context of our model, except for smoking, the results imply that the extensive margin effect of the bias dominates the intensive margin effect. In other words, people who overestimate their health engage in a suboptimally

\footnotetext{
${ }^{13}$ We also eliminate respondents who presumably guessed with $\widetilde{r}_{i}=50$. However, the results are robust to eliminating these respondents.
} 
high level of unhealthy behavior because they wrongly believe that their bodies could tolerate such behavior.

\section{Conclusion}

The literature on overconfidence has shown the existence and role of biased perceptions about individual skills and characteristics across several domains. Focusing on the health domain, this paper investigates theoretically and empirically whether and how health perception biases could affect risky health behavior.

We consider two related notions, absolute and relative health perception biases. The relative measure, which is based on the difference between the objective and the perceived rank in the population health distribution, was explicitly elicited for the purpose of this study. The advantage of these measures is that they can be measured with survey data at relatively low costs. Moreover, both measures provide comparable information as we show that, under plausible conditions, they are positively correlated.

Using a simple model we show that health biases affect individual health behavior choices at both the extensive and the intensive margin. These margins operate in opposite directions. The extensive margin refers to the perceived health status, which induces an individual to engage in more risky behavior because she believes she is healthy enough to afford it. The intensive margin of health biases operates in the opposite direction: it inflates the perception of the marginal cost of risky behavior, which induces an individual to refrain from it. In the former case, health biases and risky behavior are substitutes, while in the latter case, they are complements.

Which effect dominates is an empirical question that we investigate using three German surveys. Our empirical findings are robust and consistent across the different health bias measures and the three surveys. First, we show that health perception biases are pervasive in the health domain. For example, about $30 \%$ of all respondents of a representative German survey were unaware of their high cholesterol levels, which is evidence of a widespread absolute health perception bias. Similarly, using two other representative surveys, we find that about $30 \%$ of all respondents overestimate their position in the population health distribution by at least 30 ranks, which is evidence of a relative perception bias. 
Second, we find that health perception biases are significantly linked to risky health behavior, with the notable exception of smoking. Our main finding is that people who overestimate their health are more likely to not exercise, to eat unhealthy, drink alcohol on a daily basis, and sleep fewer hours. They also have significantly higher BMIs and are more likely to be obese. Interpreted through the lenses of our model, these statistical artifacts are consistent with the notion that the extensive margin of health perception biases dominates the intensive one. In other words, people who overestimate their health engage in excessive (suboptimal) risky behavior because they believe they are healthier than they really are.

However, third, we do not find much evidence that people who accurately assess their health, or underestimate it, are more likely to engage in risky health behavior-a result that is consistent with the intensive margin of perceived health offsetting the extensive margin. Interestingly, smoking is not significantly correlated with health biases. If future research corroborates this finding, it could suggest that public health anti-smoking campaigns aimed at altering smokers' perceptions by emphasizing the health cost of smoking are less effective than alternative policy tools such as, e.g., taxation and smoking bans (Viscusi, 1990; Becker et al., 1994; Chaloupka, 1991; Gruber and Kőszegi, 2001).

In terms of policy implications, our general results show that people with biased health perceptions can be a fruitful target group for effective public health campaigns aimed at improving risky behavior. Adding regular health check-ups and screenings to the essential health benefit packages, in addition to nudging people to seek regular feedback about their health, can be a desirable policy. However, we also find that debiasing individuals' health perceptions would not only operate on the extensive margin of perceived health biases, but also affect the intensive margin. Accordingly, people could possibly engage in more risky behavior because a better than expected health assessment could reduce the fear of the negative consequences (i.e. the perceived marginal costs) of risky behavior. This result is particularly relevant when the risky behavior produces negative externalities, because the underestimation of the marginal cost to society adds to the underestimation of the individual costs.

Our study is a first step to marry research on biased beliefs and risky health behavior, both from a theoretical and an empirical perspective. Although our empirical analysis is solely based on statistical associations, we believe it is a fruitful venue of research to show the relevance of individual perceptions for health-related behavior. In particular, future research should in- 
vestigate the generalizability of our results for different countries and different institutional setups.

\section{References}

Abaluck, J. and J. Gruber (2011, June). Choice inconsistencies among the elderly: Evidence from plan choice in the medicare part d program. American Economic Review 101(4), 1180-1210.

Abaluck, J. and J. Gruber (2016). Choice inconsistencies among the elderly: Evidence from plan choice in the Medicare Part D program: Reply. American Economic Review 106(12), 3962-87.

\section{American Heart Association (2017). High blood pressure redefined for first time in 14 years: 130 is the new high. http://newsroom.heart.org/news/ high-blood-pressure-redefined-for-first-time-in-14-years-130-is-the-new-high? retrieved March 5, 2018.}

Andersen, H. H., A. Mühlbacher, M. Nübling, J. Schupp, and G. G. Wagner (2007). Computation of standard values for physical and mental health scale scores using the SOEP version of SF12v2. Journal of Applied Social Science Studies (Schmollers Jahrbuch) 127, 171-182.

Babcock, L. and G. Loewenstein (1997). Explaining bargaining impasse: The role of self-serving biases. The Journal of Economic Perspectives 11(1), 109-126.

Bago d'Uva, T., O. O'Donnell, and E. van Doorslaer (2008). Differential health reporting by education level and its impact on the measurement of health inequalities among older Europeans. International Journal of Epidemiology 37(6), 1375-1383.

Bago d'Uva, T., O. O'Donnell, and E. van Doorslaer (2017). Who can predict their own demise? heterogeneity in the accuracy and value of longevity expectations. The Journal of the Economics of Ageing, 100135.

Baker, M., M. Stabile, and C. Deri (2004). What do self-reported, objective, measures of health measure? Journal of Human Resources 39(4), 1067-1093.

Barber, B. M. and T. Odean (2001). Boys will be boys: Gender, overconfidence, and common stock investment. Quarterly Journal of Economics 116(1), 261-292.

Becker, G. S., M. Grossman, and K. M. Murphy (1994). An empirical analysis of cigarette addiction. American Economic Review 84(3), 396-418.

Becker, G. S. and K. M. Murphy (1988). A theory of rational addiction. Journal of Political Economy 96(4), 675-700.

Belot, M. (2017). Limited cognitive resources and dietary choices: Evidence from a laboratory experiment. mimeo.

Bénabou, R. and J. Tirole (2002). Self-confidence and personal motivation. The quarterly journal of economics 117(3), 871-915.

Bénabou, R. and J. Tirole (2002). Self-confidence and personal motivation. Quarterly Journal of Economics 117(3), $261-292$.

Benoît, J.-P. and J. Dubra (2011). Apparent overconfidence. Econometrica 79(5), 1591-1625. 
Bertram, L., A. Böckenhoff, I. Demuth, S. Düzel, R. Eckardt, S.-C. Li, U. Lindenberger, G. Pawelec, T. Siedler, G. G. Wagner, and E. Steinhagen-Thiessen (2014). Cohort profile: The Berlin Aging Study II (BASE-II). International Journal of Epidemiology 43(3), 703-712.

Bhargava, S., G. Loewenstein, and J. Sydnor (2017). Choose to lose: Health plan choices from a menu with dominated option. The Quarterly Journal of Economics 132(3), 1319-1372.

Böckenhoff, A., D. Saßenroth, M. Kroh, T. Siedler, P. Eibich, and G. G. Wagner (2013). The socio-economic module of the Berlin Aging Study II (SOEP-BASE): Description, structure, and questionnaire. SOEPpapers on Multidisciplinary Panel Data Research 568, DIW Berlin, The German Socio-Economic Panel (SOEP).

Burks, S. V., J. P. Carpenter, L. Goette, and A. Rustichini (2013). Overconfidence is a social signaling bias. Review of Economic Studies 80(3), 949-983.

Camerer, C. and D. Lovallo (1999). Overconfidence and excess entry: An experimental approach. The American Economic Review 89(1), pp. 306-318.

Carrera, M., H. Royer, M. Stehr, J. Sydnor, and D. Taubinsky (2018). The limits of simple implementation intentions: Evidence from a field experiment on making plans to exercise. Journal of Health Economics 62(C), 95-104.

Carrera, M., H. Royer, M. F. Stehr, and J. R. Sydnor (2020). The structure of health incentives: Evidence from a field experiment. Management Science forthcoming.

Cawley, J. and T. Philipson (1999). An empirical examination of information barriers to trade in insurance. American Economic Review 89(4), 827-846.

Cawley, J. and C. Ruhm (2011). The economics of risky health behaviors. In Handbook of Health Economics, Volume 2, Chapter Three, pp. 95-199. Elsevier.

Chaloupka, F. (1991). Rational addictive behavior and cigarette smoking. Journal of Political Economy 99(4), 722-742.

Charness, G., J. van de Ven, and A. Rustichini (2018). Self-confidence and strategic behavior. Experimental Economics 21(1), 72-98.

Choi, A. and J. Cawley (2018). Health disparities across education: The role of differential reporting error. Health Economics 27(3), e1-e29.

Cowan, B. W. (2018). Sources of bias in teenagers' college expectations. Social Science Quarterly 99(1), 136-153.

Cutler, D. M., E. L. Glaeser, and J. M. Shapiro (2003). Why have americans become more obese? Journal of Economic Perspectives 17(3), 93-118.

Darden, M. (2017). Smoking, expectations, and health: a dynamic stochastic model of lifetime smoking behavior. Journal of Political Economy 125(5), 1465-1522.

Davillas, A. and S. Pudney (2017). Concordance of health states in couples: Analysis of selfreported, nurse administered and blood-based biomarker data in the UK Understanding Society panel. Journal of Health Economics 56, 87-102.

Della Vigna, S. and U. Malmendier (2006). Paying not to go to the gym. American Economic Review 96(3), 694-719. 
Di Girolamo, A., G. W. Harrison, M. I. Lau, and J. T. Swarthout (2015). Subjective belief distributions and the characterization of economic literacy. Journal of Behavioral and Experimental Economics (formerly The Journal of Socio-Economics) 59(C), 1-12.

Di Tella, R., R. Perez-Truglia, A. Babino, and M. Sigman (2015). Conveniently upset: Avoiding altruism by distorting beliefs about others' altruism. American Economic Review 105(11), 341642.

Dohmen, T., A. Falk, D. Huffman, U. Sunde, J. Schupp, and G. G. Wagner (2011). Individual risk attitudes: Measurement, determinants, and behavioral consequences. Journal of the European Economic Association 9(3), 522-550.

Friehe, T. and M. Pannenberg (2019). Overconfidence over the lifespan: Evidence from germany. Journal of Economic Psychology 74, 102207.

Goette, L., S. Bendahan, J. Thoresen, F. Hollis, and C. Sandi (2015). Stress pulls us apart: trait anxiety modulates the response of self-confidence to stress. Psychoneuroendocrinology 54, 115 $-123$.

Gruber, J. and B. Kőszegi (2001). Is Addiction "Rational"? Theory and Evidence. Quarterly Journal of Economics 116(4), 1261-1303.

Handel, B. R. and J. T. Kolstad (2015). Health insurance for "humans": Information frictions, plan choice, and consumer welfare. American Economic Review 105(8), 2449-2500.

Harris, M. C. (2017). Imperfect information on physical activity and caloric intake. Economics \& Human Biology 26(C), 112-125.

Harrison, G. and E. Rutström (2006). Eliciting subjective beliefs about mortality risk orderings. Environmental E Resource Economics 33(3), 325-346.

Harrison, G. W. (2015). Eliciting Subjective Beliefs of Health Risks. mimeo.

Harrison, G. W., J. Martínez-Correa, J. T. Swarthout, and E. R. Ulm (2017). Scoring rules for subjective probability distributions. Journal of Economic Behavior \& Organization 134(C), 430448.

Harrison, G. W., J. Martńez-Correa, J. T. Swarthout, and E. R. Ulm (2015). Eliciting subjective probability distributions with binary lotteries. Economics Letters 127(C), 68-71.

Heidhues, P., B. Kőszegi, and P. Strack (2019). Overconfidence and prejudice. memo.

Himmler, O. and T. Koenig (2012). Self-evaluations and performance: Evidence from adolescence. Hannover Economic Papers (HEP) dp-507, Leibniz Universität Hannover, Wirtschaftswissenschaftliche Fakultät.

Jürges, H. (2007). True health vs response styles: exploring cross-country differences in selfreported health. Health Economics 16(2), 163-178.

Jürges, H. (2008). Self-assessed health, reference levels and mortality. Applied Economics 40(5), 569-582.

Ketcham, J. D., N. V. Kuminoff, and C. A. Powers (2016, December). Choice inconsistencies among the elderly: Evidence from plan choice in the Medicare Part D program: Comment. American Economic Review 106(12), 3932-61.

Ketcham, J. D., C. Lucarelli, E. J. Miravete, and M. C. Roebuck (2012, May). Sinking, swimming, or learning to swim in Medicare Part D. American Economic Review 102(6), 2639-73. 
Köszegi, B. (2006). Ego utility, overconfidence, and task choice. Journal of the European Economic Association 4(4), 673-707.

Lindeboom, M. and E. van Doorslaer (2004). Cut-point shift and index shift in self-reported health. Journal of Health Economics 23(6), 1083-1099.

Linnér, R. K., P. Biroli, E. Kong, S. F. W. Meddens, R. Wedow, M. A. Fontana, M. Lebreton, A. Abdellaoui, A. R. Hammerschlag, M. G. Nivard, A. Okbay, C. A. Rietveld, P. N. Timshel, S. P. Tino, M. Trzaskowski, R. d. Vlaming, C. L. Zünd, Y. Bao, L. Buzdugan, A. H. Caplin, C.Y. Chen, P. Eibich, P. Fontanillas, J. R. Gonzalez, P. K. Joshi, V. Karhunen, A. Kleinman, R. Z. Levin, C. M. Lill, G. A. Meddens, G. Muntané, S. Sanchez-Roige, F. J. v. Rooij, E. Taskesen, Y. Wu, F. Zhang, A. Auton, J. D. Boardman, D. W. Clark, A. Conlin, C. C. Dolan, U. Fischbacher, P. J. F. Groenen, K. M. Harris, G. Hasler, A. Hofman, M. A. Ikram, S. Jain, R. Karlsson, R. C. Kessler, M. Kooyman, J. MacKillop, M. Männikkö, C. Morcillo-Suarez, M. B. McQueen, K. M. Schmidt, M. C. Smart, M. Sutter, A. R. Thurik, A. G. Uitterlinden, J. White, H. d. Wit, J. Yang, L. Bertram, D. Boomsma, T. Esko, E. Fehr, D. A. Hinds, M. Johannesson, M. Kumari, D. Laibson, P. K. E. Magnusson, M. N. Meyer, A. Navarro, A. A. Palmer, T. H. Pers, D. Posthuma, D. Schunk, M. B. Stein, R. Svento, H. Tiemeier, P. R. H. J. Timmers, P. Turley, R. J. Ursano, G. G. Wagner, J. F. Wilson, J. Gratten, J. J. Lee, D. Cesarini, D. J. Benjamin, P. D. Koellinger, and J. P. Beauchamp (2019). Genome-wide association analyses of risk tolerance and risky behaviors in over 1 million individuals identify hundreds of loci and shared genetic influences. Nature Genetics 51, 245-257.

Merkle, C. and M. Weber (2011). True overconfidence: The inability of rational information processing to account for apparent overconfidence. Organizational Behavior and Human Decision Processes 116(2), 262-271.

Moore, D. A. and P. J. Healy (2008). The trouble with overconfidence. Psychological review 115(2), 502.

Ortoleva, P. and E. Snowberg (2015a). Overconfidence in political behavior. American Economic Review 105(2), 504-35.

Ortoleva, P. and E. Snowberg (2015b). Overconfidence in political behavior. The American Economic Review 105(2), 504-535.

Rabin, M. (2013, June). Incorporating limited rationality into economics. Journal of Economic Literature 51(2), 528-43.

RAND (1995). User's manual for the medical outcomes study (mos) core measures of healthrelated quality of life. Technical report.

Richter, D., M. Metzing, M. Weinhardt, and J. Schupp (2013). SOEP Scales ManualErhebungsinstrumente Berliner Altersstudie II. SOEP Survey Papers: Series C Data Documentations (Datendokumentationen) 138. panel.gsoep.de/soep-docs/ surveypapers/diw_ssp0138.pdf, retrieved January 17, 2014.

Richter, D. and J. Schupp (2015). The SOEP Innovation Sample (SOEP IS). Schmollers Jahrbuch 135(3), 389-399.

Richter, D. and J. Schupp (2017). Questionnaire for the soep innovation sample (boost sample). SOEP Survey Papers 454, DIW Berlin, The German Socio-Economic Panel (SOEP).

Robert Koch Institut (2012). German National Health Survey East-West 1991 (GNHSEW91), Public Use File OW91. Robert Koch Institut. http://www.rki.de/DE/Content/ Gesundheitsmonitoring/PublicUseFiles/informationen_datensaetze/ info_datensaetze_node.html, last accessed on June 11, 2016. 
Royer, H., M. Stehr, and J. Sydnor (2015). Incentives, commitments, and habit formation in exercise: Evidence from a field experiment with workers at a fortune-500 company. American Economic Journal: Applied Economics 7(3), 51-84.

Sandroni, A. and F. Squintani (2007). Overconfidence, insurance, and paternalism. The American Economic Review 97(5), 1994-2004.

Santos-Pinto, L. and J. Sobel (2005). A model of positive self-image in subjective assessments. American Economic Review 95(5), 1386-1402.

Sharot, T. (2011). The optimism bias. Current biology 21(23), R941-R945.

Spinnewijn, J. (2015). Unemployed but optimistic: Optimal insurance design with biased beliefs. Journal of the European Economic Association 13(1), 130-167.

Spitzer, S. and D. Weber (2019). Who is telling the truth? biases in self-reported physical and cognitive health status of older Europeans. PLoS ONE 10(14), e0223526.

Strulik, H. and T. Trimborn (2018). Hyperbolic discounting can be good for your health. Center for European, Governance and Economic Development Research Discussion Papers 335, University of Goettingen, Department of Economics.

Tiefenbeck, V., L. Goette, K. Degen, R. Lalive, and T. Staake (2018). Overcoming salience bias: How real-time feedback fosters resource conservation. Management Science 64(3), 1458-1476.

Viscusi, W. K. (1990). Do smokers underestimate risks? Journal of Political Economy 98(6), 12531269.

Wagner, G. G., J. R. Frick, and J. Schupp (2007). The German Socio-Economic Panel Study (SOEP)-scope, evolution and enhancements. Schmollers Jahrbuch : Journal of Applied Social Science Studies / Zeitschrift für Wirtschafts- und Sozialwissenschaften 127(1), 139-169.

Weinberg, B. A. (2006). A model of overconfidence. Working paper, Ohio State University.

Weinstein, N. (1989). Optimistic biases about personal risks. Science 246(4935), 1232-1233.

Weinstein, N. D. (1980). Unrealistic optimism about future life events. Journal of Personality and Social Psychology 39(5), 806.

Ziebarth, N. R. (2010). Measurement of health, health inequality, and reporting heterogeneity. Social Science $\mathcal{E}$ Medicine 71, 116-124. 


\section{Figures}

Figure 1: Absolute Health Perception Bias about High Cholesterol Levels

(a) High Cholesterol Levels

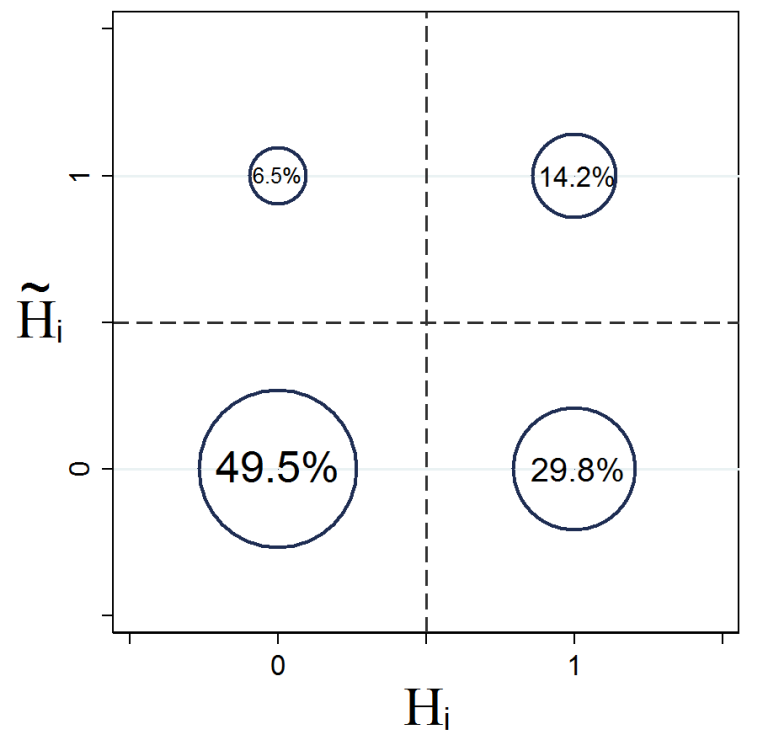

(b) High Blood Pressure

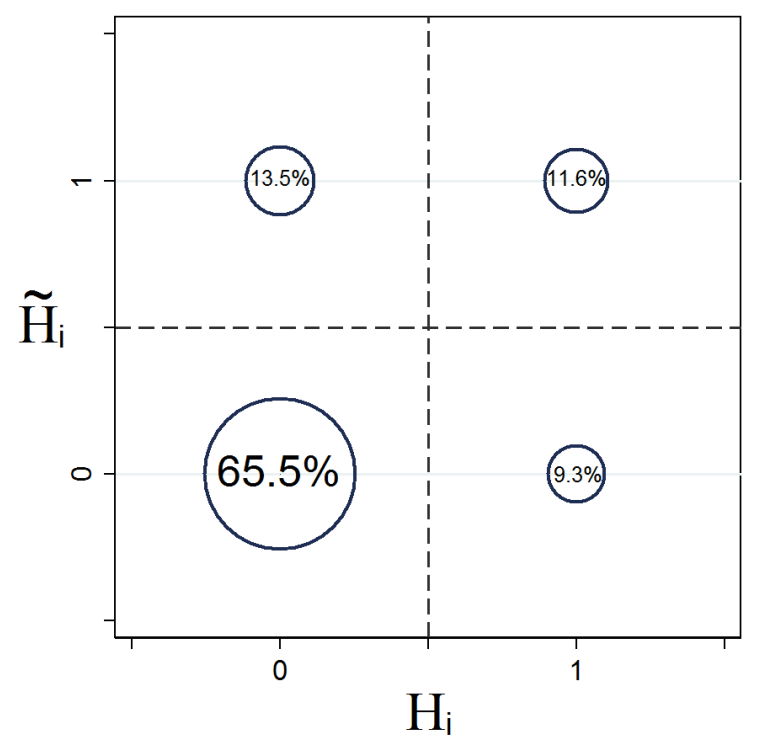

Source: GNHSEW91. See Section 4.3 and 5 for more details.

Figure 2: Perceived Population Share in Better Health $\left(\widetilde{b_{i}}\right)$
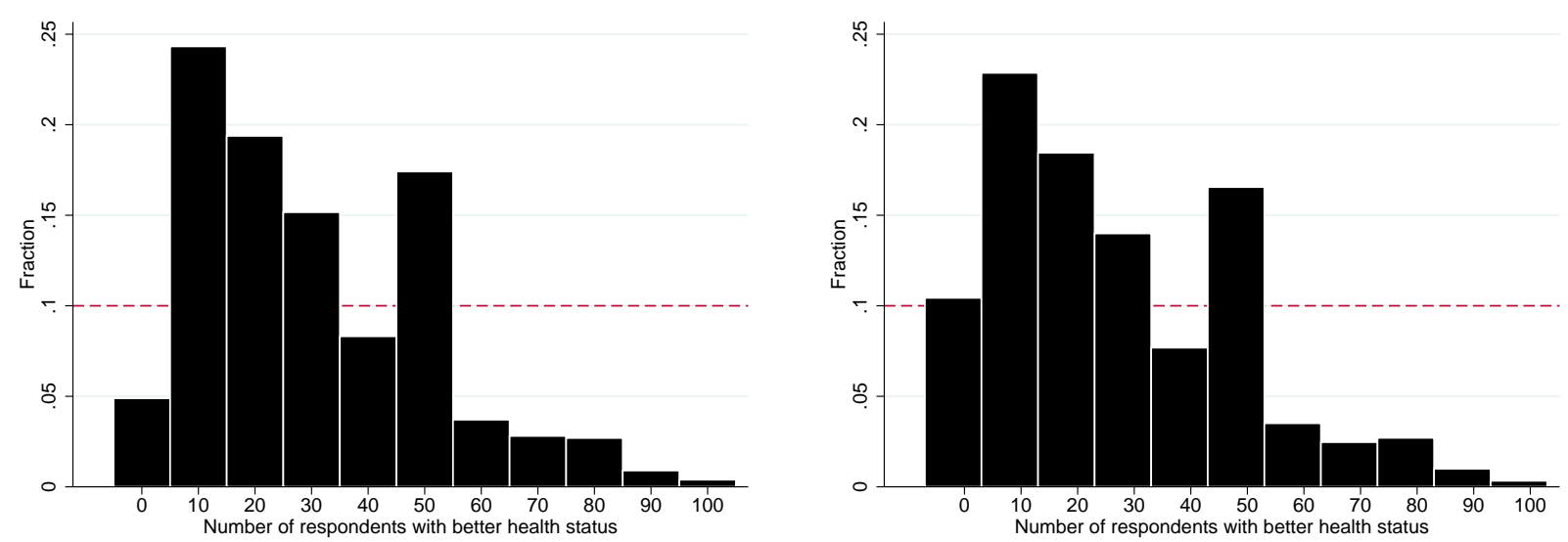

Sources: BASE-II (left panel), SOEP-IP (right panel). Responses to the question are plotted: "Imagine one would randomly select 100 people in your age. How many of those 100 people would be in better health than you?" People answering 0 believe nobody is in better health; people answering 99 believe everybody is healthier than them." 
Figure 3: Actual $\left(r_{i}\right)$ and Perceived $\left(\tilde{r}_{i}\right)$ Ranking in Population Health Distribution
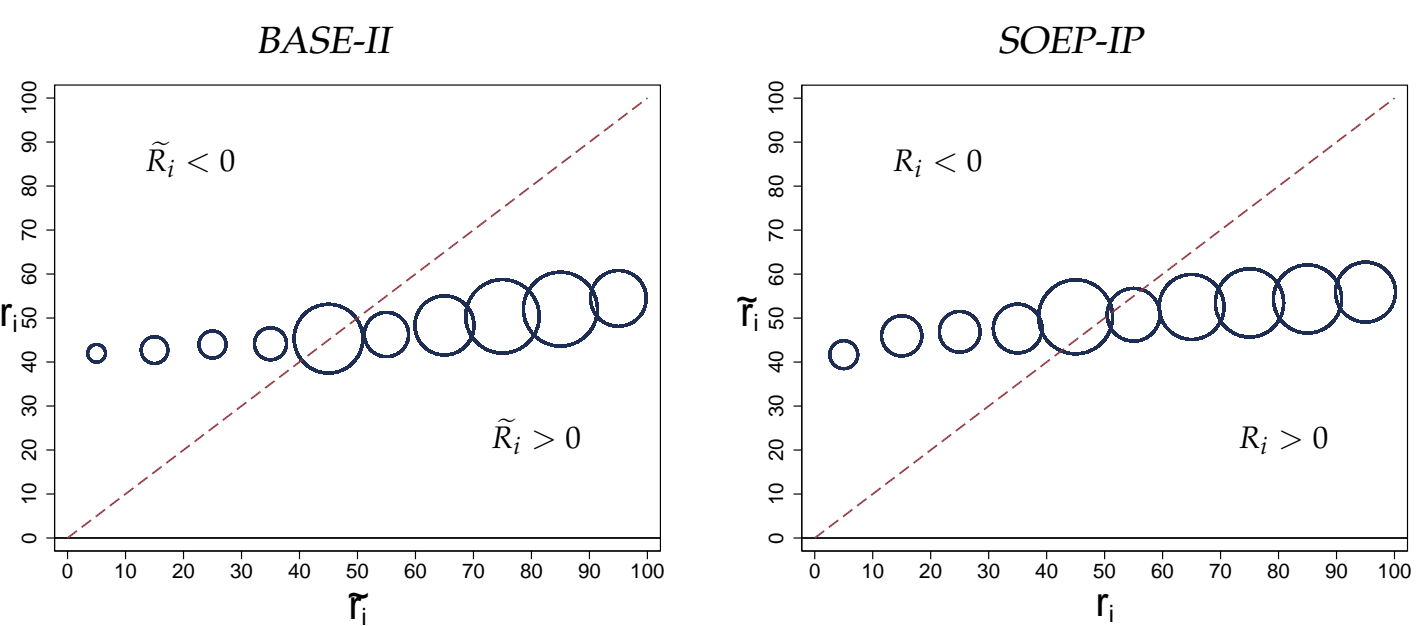

Source: BASE-II. Relative health perception biases are defined as $\widetilde{R}_{i}=\widetilde{r_{i}}-r_{i}$, with $\widetilde{r_{i}}=1-\widetilde{b_{i}}$, see Figure 2 and main text. The true rank in the population health distribution, $r_{i}$, is based on the SF12 indicator.

Figure 4: Distribution of $R_{i}$ Based on (a) SAH, (b) SF12 in SOEP-IP
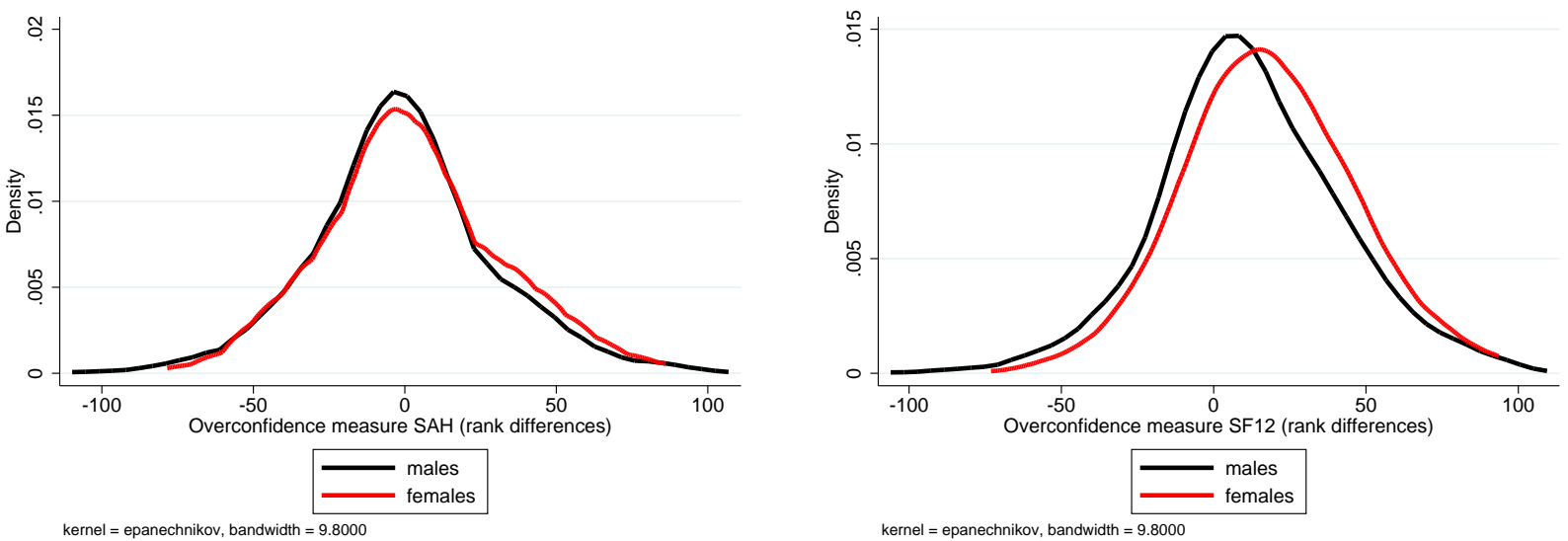

Source: SOEP-IP. Figure displays distributions of $\widetilde{R_{i}}=\widetilde{r_{i}}-r_{i}$ in the representative SOEP-IP, with $\tilde{r_{i}}=1-\widetilde{b_{i}}$, see Figure 2 and main text. Subfigure (a) uses SAH and subfigure (b) uses the SF12 as $r_{i}$. 
Figure 5: Absolute Health Perception Bias (High Cholesterol) and Risky Health Behavior
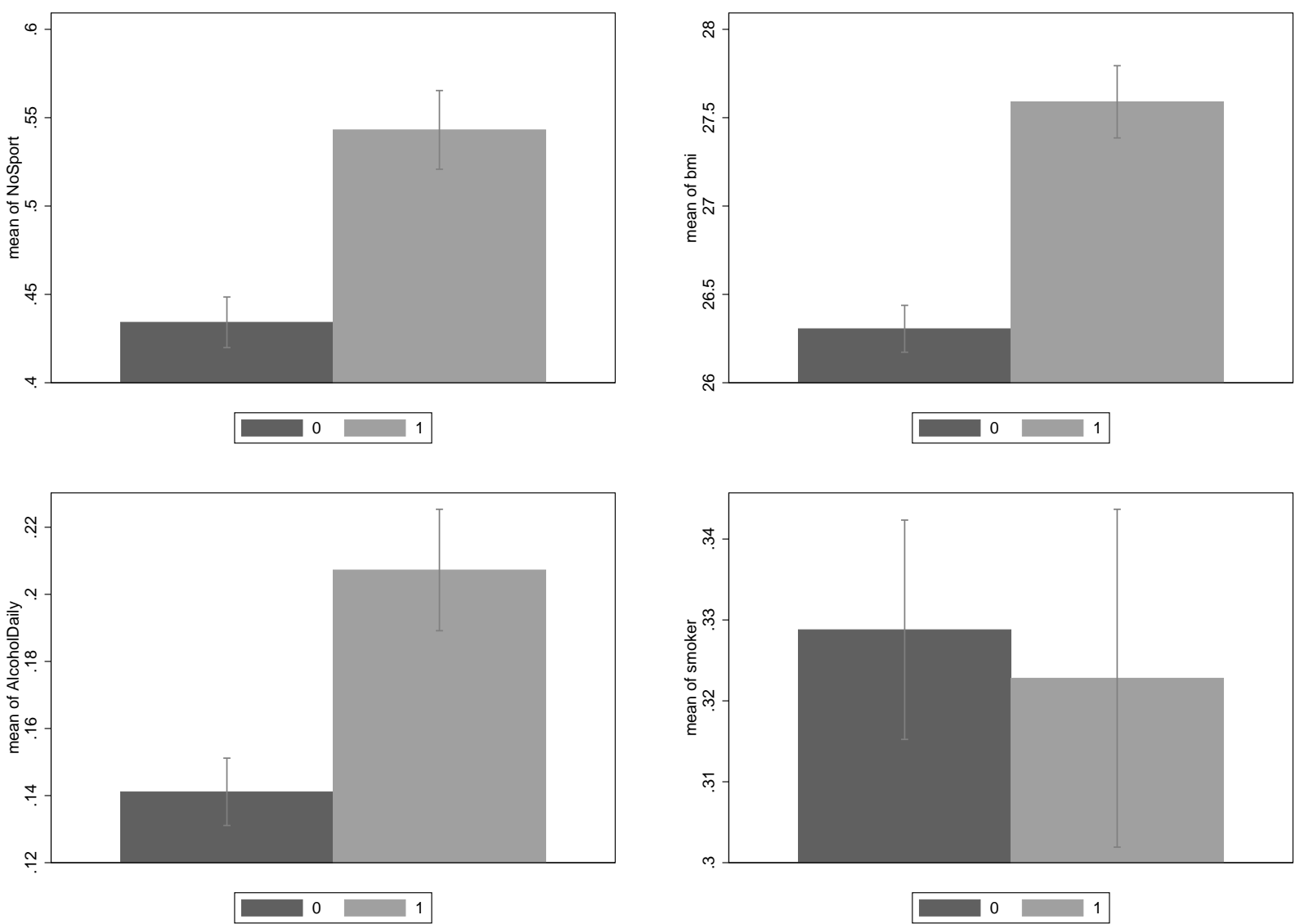

Source: GNHSEW91, own calculations, own illustration. Bar diagrams show, along with 95\% confidence intervals, the (a) share of respondents who do not exercise, (b) mean BMI, as well as the share of respondents who (c) drink alcohol daily and (d) smoke. 
Figure 6: Absolute Health Perception Bias (High Blood Pressure) and Risky Health Behavior
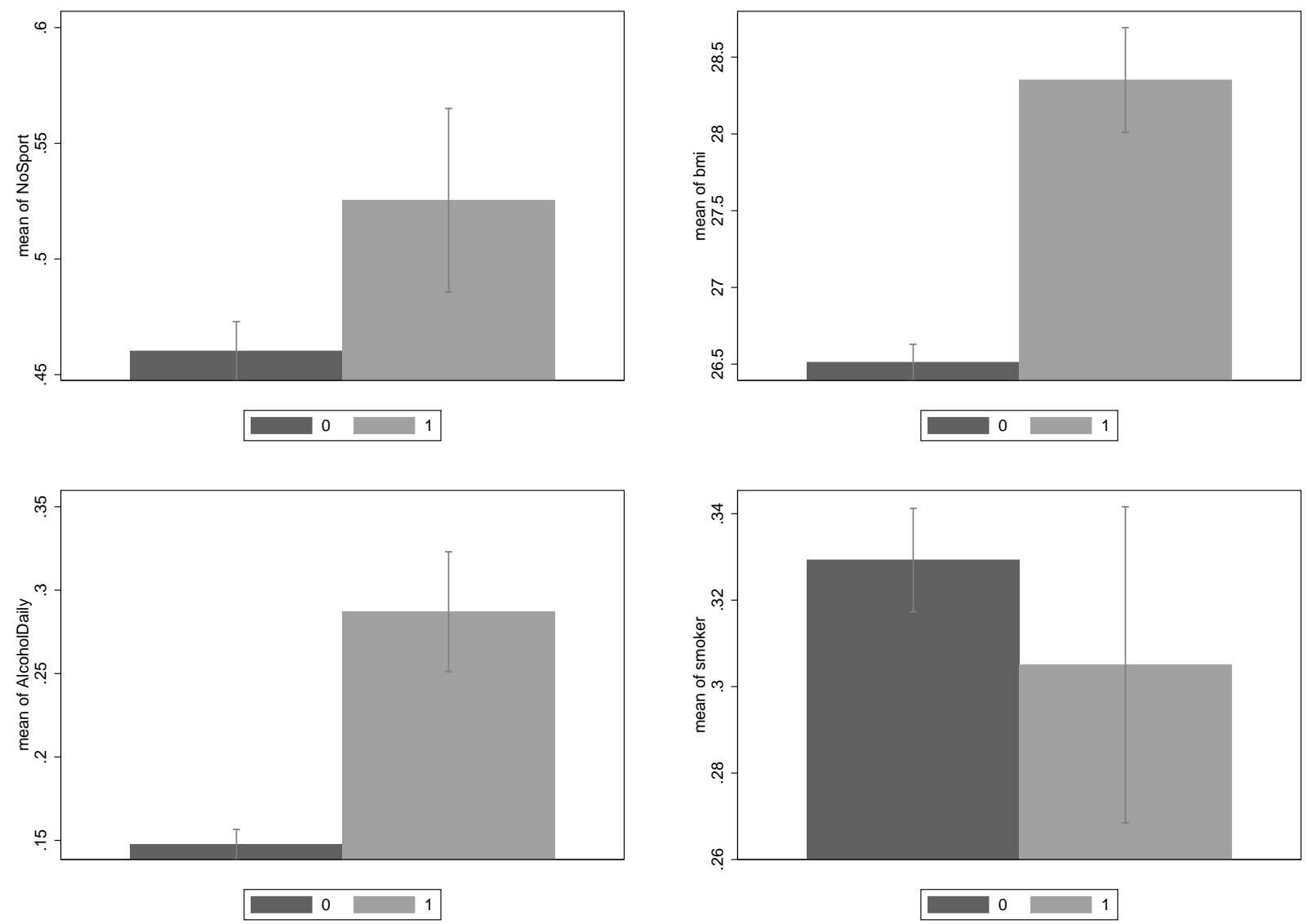

Source: GNHSEW91, own calculations, own illustration. Bar diagrams show, along with $95 \%$ confidence intervals, the (a) share of respondents who do not exercise, (b) mean BMI, as well as the share of respondents who (c) drink alcohol daily and (d) smoke. 


\section{Figure 7: Relative Health Perception Bias and Risky Health Behavior}
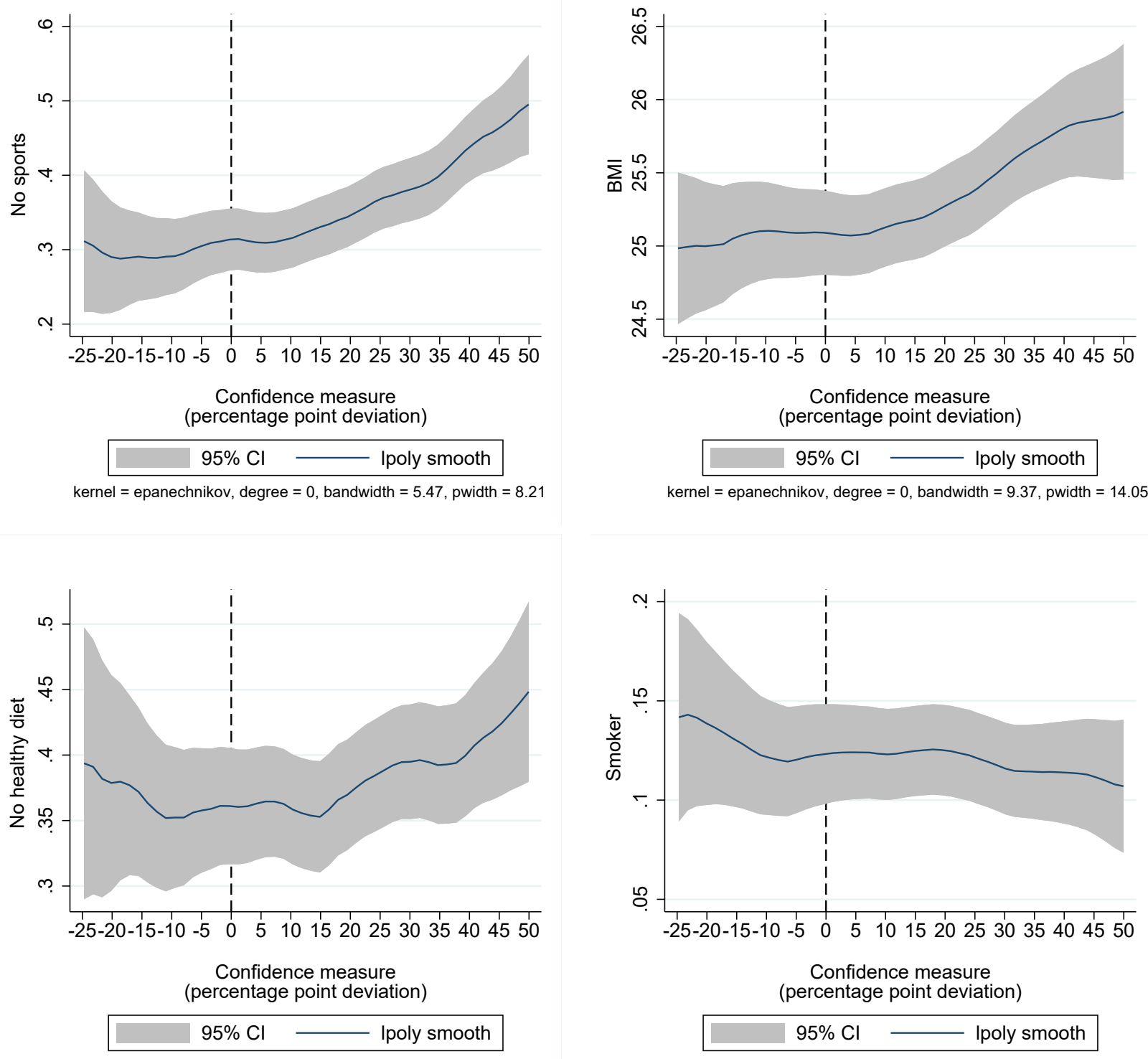

Source: BASE-II, own calculations, own illustration. Figure shows non-parametric kernel-weighted local polynomial smoothing plots. The y-axis shows (a) the likelihood that respondents do not exercise, (b) their BMI, as well as the likelihood that respondents (c) have an unhealthy diet, (d) smoke. 
Figure 8: Relative Health Perception Biases and the Sleep Gap to 8 Hours (SOEP-IP)
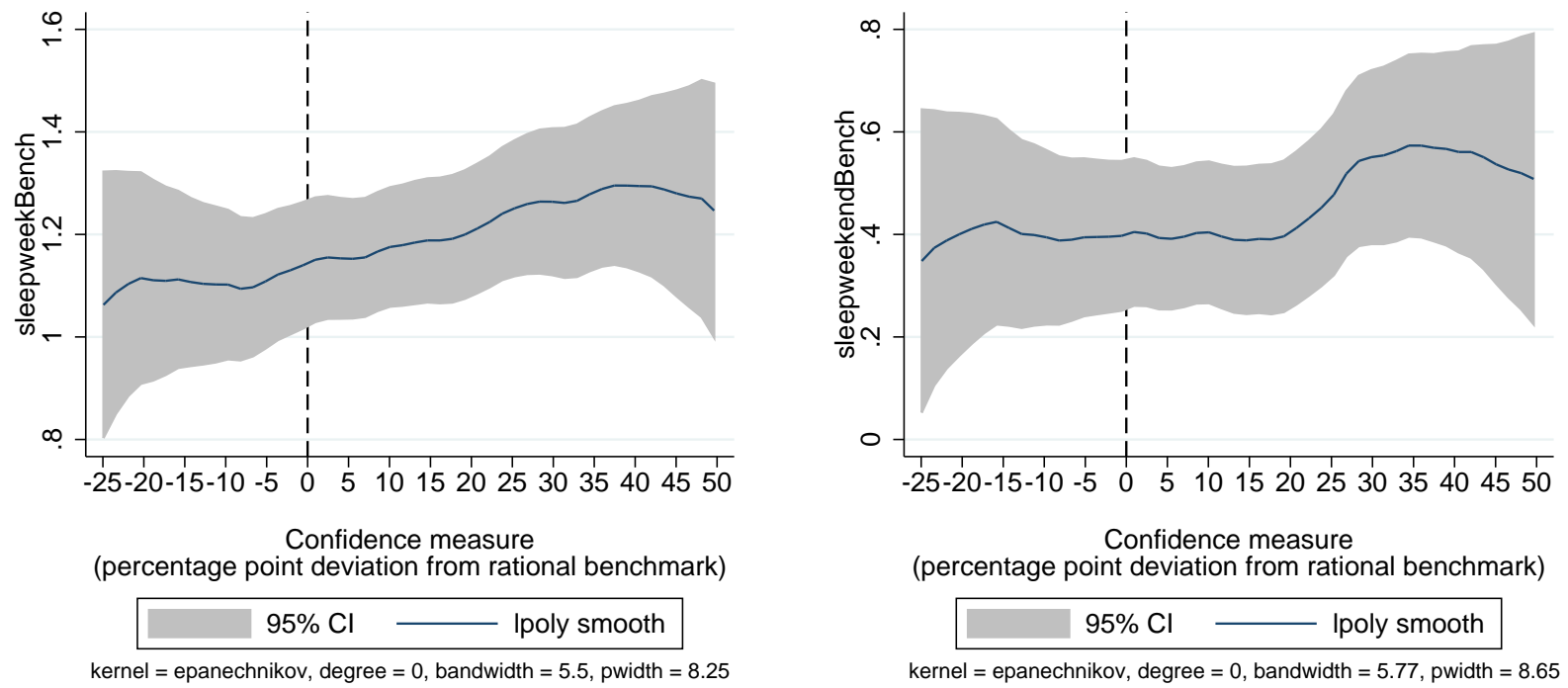

Source: SOEP-IP, own calculations, own illustration. Figure shows non-parametric kernel-weighted local polynomial smoothing plots. The y-axis shows the difference between 8 hours of sleep and actual hours of sleep (a) during the week, (b) on weekends. 
Table 1: Relative Perception Bias and Likelihood to Not Exercise

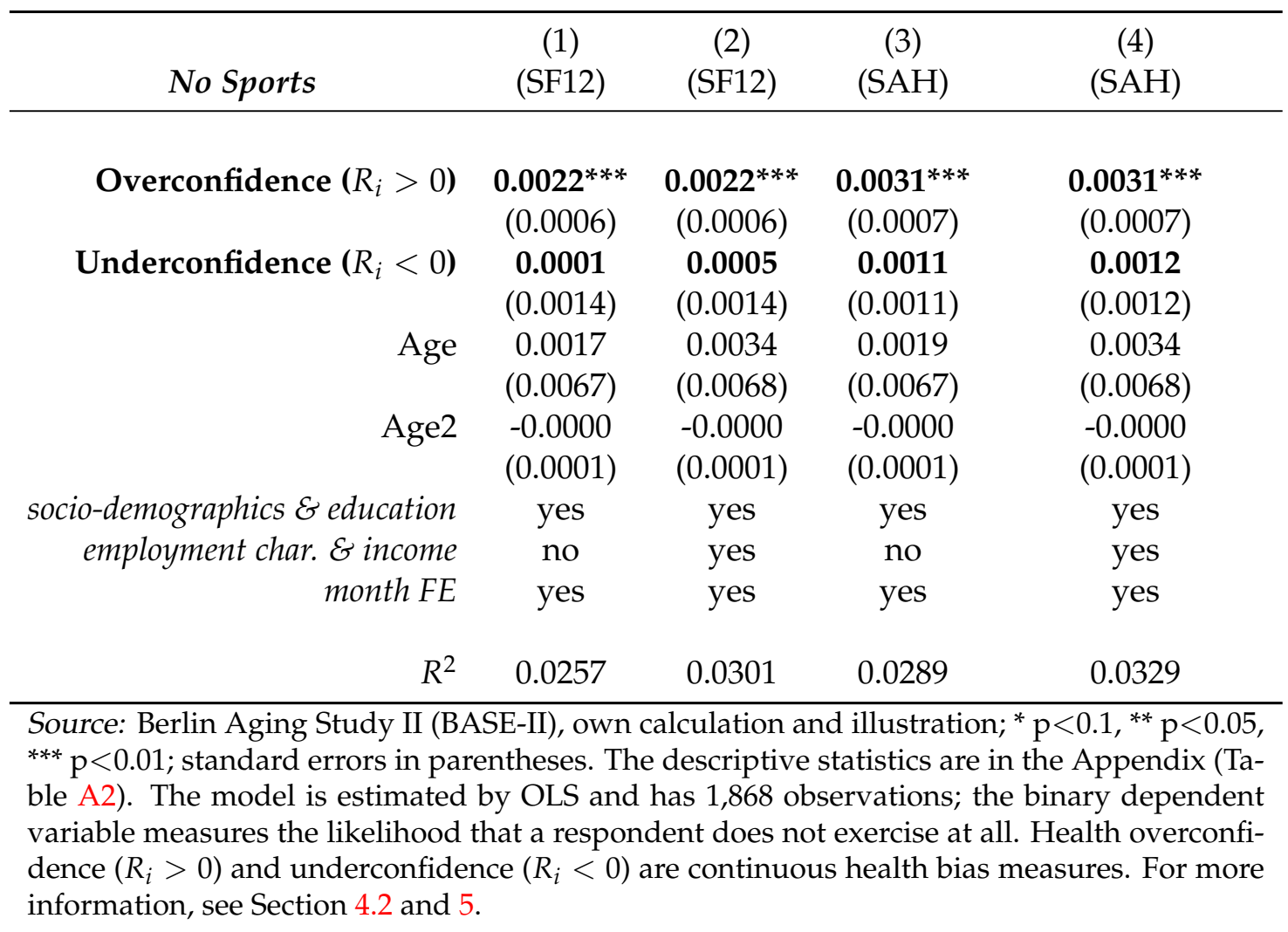


Table 2: Relative Perception Bias and Likelihood to be Obese

\begin{tabular}{|c|c|c|c|c|}
\hline Obesity & $\begin{array}{c}(1) \\
(\mathrm{SF} 12)\end{array}$ & $\begin{array}{c}(2) \\
(\mathrm{SF} 12)\end{array}$ & $\begin{array}{c}(3) \\
(\mathrm{SAH})\end{array}$ & $\begin{array}{c}(4) \\
(\mathrm{SAH})\end{array}$ \\
\hline Overconfidence $\left(R_{i}>0\right)$ & $\begin{array}{c}\mathbf{0 . 0 0 1 0} * * * \\
(0.0004)\end{array}$ & $\begin{array}{c}\mathbf{0 . 0 0 1 1}^{* * *} \\
(0.0004)\end{array}$ & $\begin{array}{c}\mathbf{0 . 0 0 2 2} * * * \\
(0.0005)\end{array}$ & $\begin{array}{c}\mathbf{0 . 0 0 2 2}^{* * *} \\
(0.0005)\end{array}$ \\
\hline Underconfidence $\left(R_{i}<0\right)$ & $\begin{array}{c}\mathbf{0 . 0 0 0 8} \\
(0.0010)\end{array}$ & $\begin{array}{c}\mathbf{0 . 0 0 0 8} \\
(0.0010)\end{array}$ & $\begin{array}{c}-\mathbf{- 0 . 0 0 0 2} \\
(0.0008)\end{array}$ & $\begin{array}{c}-0.0002 \\
(0.0008)\end{array}$ \\
\hline Age & $\begin{array}{l}0.0097^{* *} \\
(0.0043)\end{array}$ & $\begin{array}{l}0.0109^{* *} \\
(0.0044)\end{array}$ & $\begin{array}{l}0.0102^{* *} \\
(0.0043)\end{array}$ & $\begin{array}{c}0.0113^{* * *} \\
(0.0043)\end{array}$ \\
\hline Age2 & $\begin{array}{l}-0.0001^{*} \\
(0.0000)\end{array}$ & $\begin{array}{c}-0.0001^{* *} \\
(0.0000)\end{array}$ & $\begin{array}{c}-0.0001^{* *} \\
(0.0000)\end{array}$ & $\begin{array}{c}-0.0001^{* *} \\
(0.0000)\end{array}$ \\
\hline \multirow{3}{*}{$\begin{array}{r}\text { socio-demographics } \mathcal{E} \text { education } \\
\text { employment char. } \mathcal{E} \text { income } \\
\text { month FE }\end{array}$} & yes & yes & yes & yes \\
\hline & no & yes & no & yes \\
\hline & yes & yes & yes & yes \\
\hline$R^{2}$ & 0.0271 & 0.0306 & 0.0360 & 0.0391 \\
\hline \multicolumn{5}{|c|}{$\begin{array}{l}\text { Source: Berlin Aging Study II (BASE-II), own calculation and illustration; }{ }^{*} \mathrm{p}<0.1{ }^{* *} \mathrm{p}<0.05 \text {, } \\
{ }^{* * *} \mathrm{p}<0.01 \text {; standard errors in parentheses. The descriptive statistics are in the Appendix (Ta- } \\
\text { ble A2). The model is estimated by OLS and has } 1,868 \text { observations; the binary dependent } \\
\text { variable measures the likelihood that a respondent is obese (BMI }>30) \text {. Health overconfidence } \\
\left(R_{i}>0\right) \text { and underconfidence }\left(R_{i}<0\right) \text { are continuous health bias measures. More informa- } \\
\text { tion on the variables, see Section } 4.2 \text { and } 5 \text {. }\end{array}$} \\
\hline
\end{tabular}


Table 3: Relative Perception Bias and Having an Unhealthy Diet

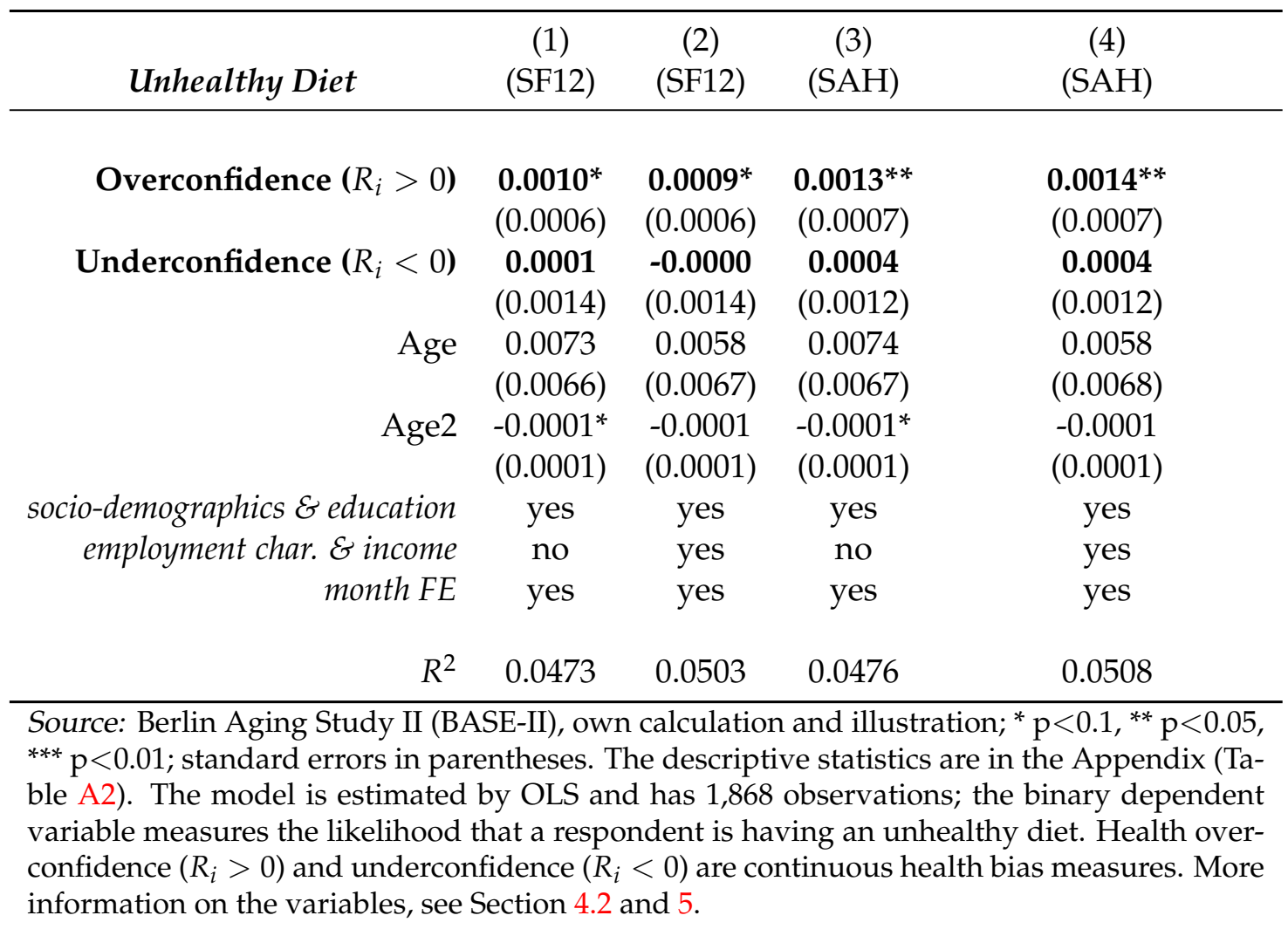


Table 4: Relative Perception Bias and Smoking

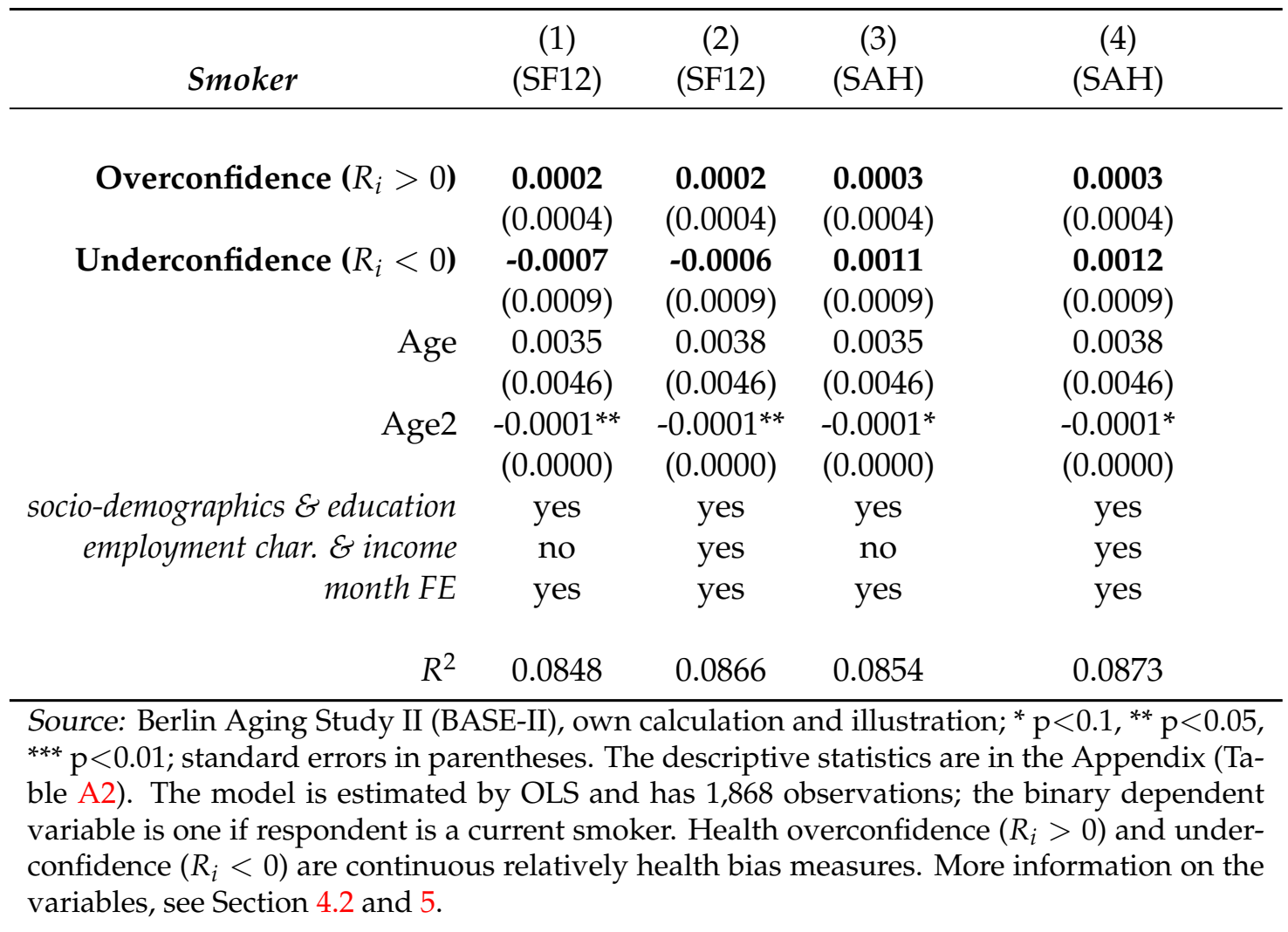


Table 5: Relative Perception Bias and Sleep Gap to 8 Hours

\begin{tabular}{rcccc}
\hline & $(1)$ & $(2)$ & $(3)$ & $(4)$ \\
Sleep Gap to 8 Hours & $(\mathrm{SF} 12)$ & $(\mathrm{SF} 12)$ & $(\mathrm{SAH})$ & $(\mathrm{SAH})$ \\
\hline Overconfidence $\left(R_{i}>0\right)$ & $\mathbf{0 . 0 0 3 4 ^ { * }}$ & $\mathbf{0 . 0 0 3 4 ^ { * }}$ & $\mathbf{0 . 0 0 5 3 ^ { * * }}$ & $\mathbf{0 . 0 0 5 1 ^ { * * }}$ \\
& $(0.0019)$ & $(0.0019)$ & $(0.0022)$ & $(0.0022)$ \\
Underconfidence $\left(R_{i}<0\right)$ & $-\mathbf{0 . 0 0 8 0 ^ { * * }}$ & $\mathbf{- 0 . 0 0 7 8 ^ { * * }}$ & $\mathbf{- 0 . 0 0 1 6}$ & $\mathbf{- 0 . 0 0 1 7}$ \\
& $(0.0038)$ & $(0.0038)$ & $(0.0028)$ & $(0.0028)$ \\
Age & $0.0547^{* * *}$ & $0.0464^{* * *}$ & $0.0549^{* * *}$ & $0.0459^{* * *}$ \\
& $(0.0112)$ & $(0.0125)$ & $(0.0112)$ & $(0.0125)$ \\
Age2 & $-0.0006^{* * *}$ & $-0.0005^{* * *}$ & $-0.0006^{* * *}$ & $-0.0005^{* * *}$ \\
& $(0.0001)$ & $(0.0001)$ & $(0.0001)$ & $(0.0001)$ \\
sociodem. E educ. & yes & yes & yes & yes \\
pers.traits $\mathcal{E}$ behav.attr. & no & yes & no & yes \\
month FE & yes & yes & yes & yes \\
& & & & \\
$R^{2}$ & 0.0358 & 0.0434 & 0.0332 & 0.0383
\end{tabular}

Source: SOEP-IP, own calculation and illustration; ${ }^{*} \mathrm{p}<0.1,{ }^{* *} \mathrm{p}<0.05,{ }^{* * *} \mathrm{p}<0.01$; standard errors in parentheses. The descriptive statistics are in the Appendix (Table A3). The model is estimated by OLS and has 1,444 observations; the dependent variable measures the gap between the actual hours of sleep during the week and eight hours. Health overconfidence $\left(R_{i}>0\right)$ and underconfidence $\left(R_{i}<0\right)$ are continuous health bias measures. More information on the variables, see Section 4.3 and 5. 
Table 6: Robustness Ceiling Effects: Trimmed $R_{i}$ Distribution

\begin{tabular}{|c|c|c|c|c|c|c|c|c|}
\hline & $(1)$ & $(2)$ & (3) & $(4)$ & $(5)$ & (6) & $(7)$ & $(8)$ \\
\hline & \multicolumn{2}{|c|}{ No Sports } & \multicolumn{2}{|c|}{$B M I$} & \multicolumn{2}{|c|}{ Unhealthy Diet } & \multicolumn{2}{|c|}{ Smoker } \\
\hline Overconfidence $\left(R_{i}>0\right)$ & $\begin{array}{r}0.0022^{* * *} \\
(0.0006)\end{array}$ & $\begin{array}{c}0.0016^{* *} \\
(0.0007)\end{array}$ & $\begin{array}{r}0.0157^{* * *} \\
(0.0056)\end{array}$ & $\begin{array}{r}0.0168^{* * *} \\
(0.0061)\end{array}$ & $\begin{array}{r}0.0017^{* * *} \\
(0.0006)\end{array}$ & $\begin{array}{c}0.0012^{*} \\
(0.0007)\end{array}$ & $\begin{array}{r}0.0003 \\
(0.0004)\end{array}$ & $\begin{array}{r}0.0003 \\
(0.0004)\end{array}$ \\
\hline Underconfidence $\left(R_{i}<0\right)$ & $\begin{array}{r}0.0013 \\
(0.0016)\end{array}$ & $\begin{array}{r}0.0018 \\
(0.0017)\end{array}$ & $\begin{array}{c}0.0375^{* *} \\
(0.0149)\end{array}$ & $\begin{array}{c}0.0374^{* *} \\
(0.0148)\end{array}$ & $\begin{array}{r}0.0023 \\
(0.0016)\end{array}$ & $\begin{array}{r}0.0026 \\
(0.0016)\end{array}$ & $\begin{array}{r}-0.0005 \\
(0.0012)\end{array}$ & $\begin{array}{r}-0.0004 \\
(0.0012)\end{array}$ \\
\hline$R^{2}$ & 0.0185 & 0.0472 & 0.1112 & 0.1347 & 0.0461 & 0.1007 & 0.0704 & 0.0861 \\
\hline socio-demographics & yes & yes & yes & yes & yes & yes & yes & yes \\
\hline month FE & yes & yes & yes & yes & yes & yes & yes & yes \\
\hline education $\mathcal{E}$ personality $\mathcal{E}$ behavorial & no & yes & no & yes & no & yes & no & yes \\
\hline
\end{tabular}


Table 7: Robustness Additional Covariates: Risk Aversion and Personality Traits

\begin{tabular}{|c|c|c|c|c|c|c|c|c|}
\hline & $(1)$ & $(2)$ & (3) & $(4)$ & $(5)$ & $(6)$ & (7) & $(8)$ \\
\hline & \multicolumn{2}{|c|}{ No Exercise } & \multicolumn{2}{|c|}{ Obese } & \multicolumn{2}{|c|}{ Unhealthy Diet } & \multicolumn{2}{|c|}{ Smoker } \\
\hline Overconfidence $\left(R_{i}>0\right)$ & $\begin{array}{c}0.0030^{* * *} \\
(0.0007)\end{array}$ & $\begin{array}{c}0.0028^{* * *} \\
(0.0007)\end{array}$ & $\begin{array}{c}0.0021^{* * *} \\
(0.0005)\end{array}$ & $\begin{array}{c}0.0022^{* * *} \\
(0.0005)\end{array}$ & $\begin{array}{c}0.0012^{*} \\
(0.0007)\end{array}$ & $\begin{array}{c}0.0013^{*} \\
(0.0007)\end{array}$ & $\begin{array}{c}0.0003 \\
(0.0004)\end{array}$ & $\begin{array}{c}0.0003 \\
(0.0004)\end{array}$ \\
\hline Underconfidence $\left(R_{i}<0\right)$ & $\begin{array}{c}0.0013 \\
(0.0012)\end{array}$ & $\begin{array}{c}0.0014 \\
(0.0012)\end{array}$ & $\begin{array}{l}-0.0002 \\
(0.0008)\end{array}$ & $\begin{array}{l}-0.0002 \\
(0.0008)\end{array}$ & $\begin{array}{c}0.0006 \\
(0.0012)\end{array}$ & $\begin{array}{c}0.0009 \\
(0.0011)\end{array}$ & $\begin{array}{c}0.0011 \\
(0.0009)\end{array}$ & $\begin{array}{c}0.0011 \\
(0.0009)\end{array}$ \\
\hline$R^{2}$ & 0.0377 & 0.0424 & 0.0408 & 0.0452 & 0.0596 & 0.0926 & 0.0897 & 0.0924 \\
\hline socio-demographics $\mathcal{E}$ education & yes & yes & yes & yes & yes & yes & yes & yes \\
\hline employment char. $\mathcal{E}$ income & yes & yes & yes & yes & yes & yes & yes & yes \\
\hline month FE & yes & yes & yes & yes & yes & yes & yes & yes \\
\hline risk aversion indicators & yes & no & yes & no & yes & no & yes & no \\
\hline personality traits & no & yes & no & yes & no & yes & no & yes \\
\hline
\end{tabular}

Source: Berlin Aging Study II (BASE-II), own calculation and illustration; ${ }^{*} \mathrm{p}<0.1,{ }^{* *} \mathrm{p}<0.05,{ }^{* * *} \mathrm{p}<0.01$; standard errors in parentheses. The descriptive statistics are in the Appendix (Table A2). This robustness check adds, for each health behavior outcome, either risk aversion indicators (risk-averse is $\leq 3$ and risk-loving is $\geq 8$ on a risk-aversion scale ranging from 0 to 10 ) or the Big 5 personality traits as additional covariates. The model is estimated by OLS and has 1,868 observations; the columns indicate the dependent variables. Health overconfidence $\left(R_{i}>0\right)$ and underconfidence $\left(R_{i}<0\right)$ are continuous health bias measures, using SAH to measure $H_{i}$ (results using SF12 on request). More information on the variables, see Section 4.3 and 5 . 


\section{Appendix}

Figure A1: Distribution of SAH and SF12 in BASE-II
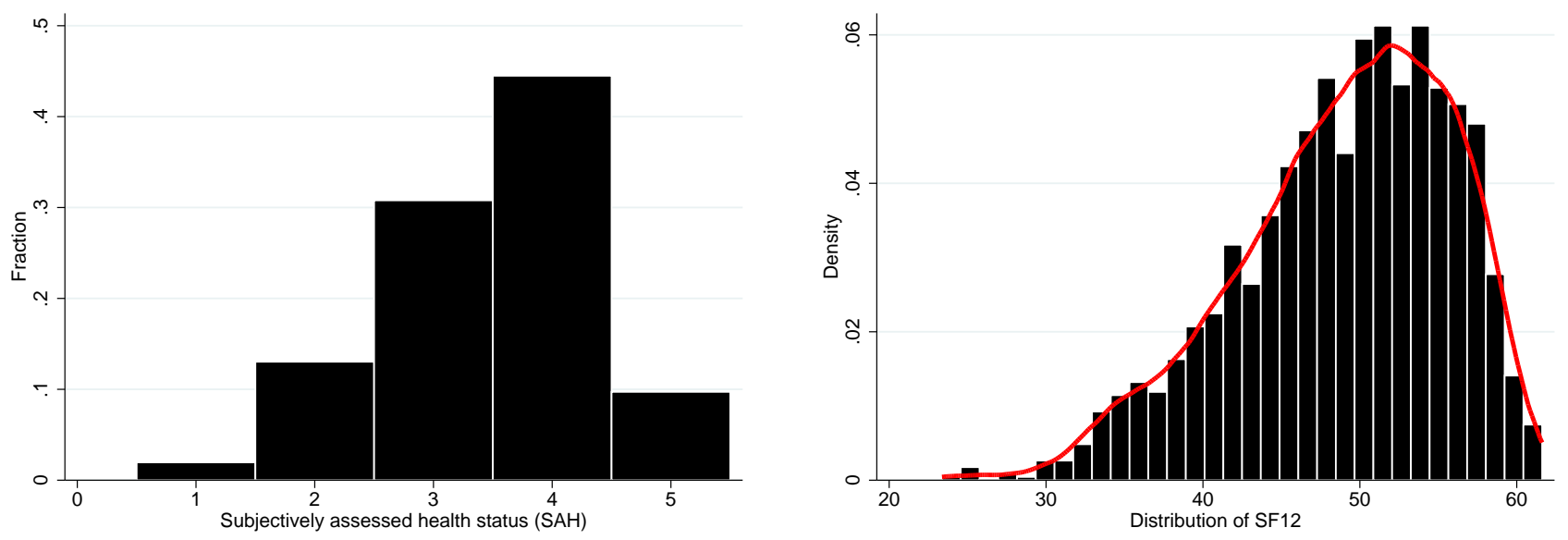

Figure A2: Distribution of SAH and SF12 in SOEP-IP
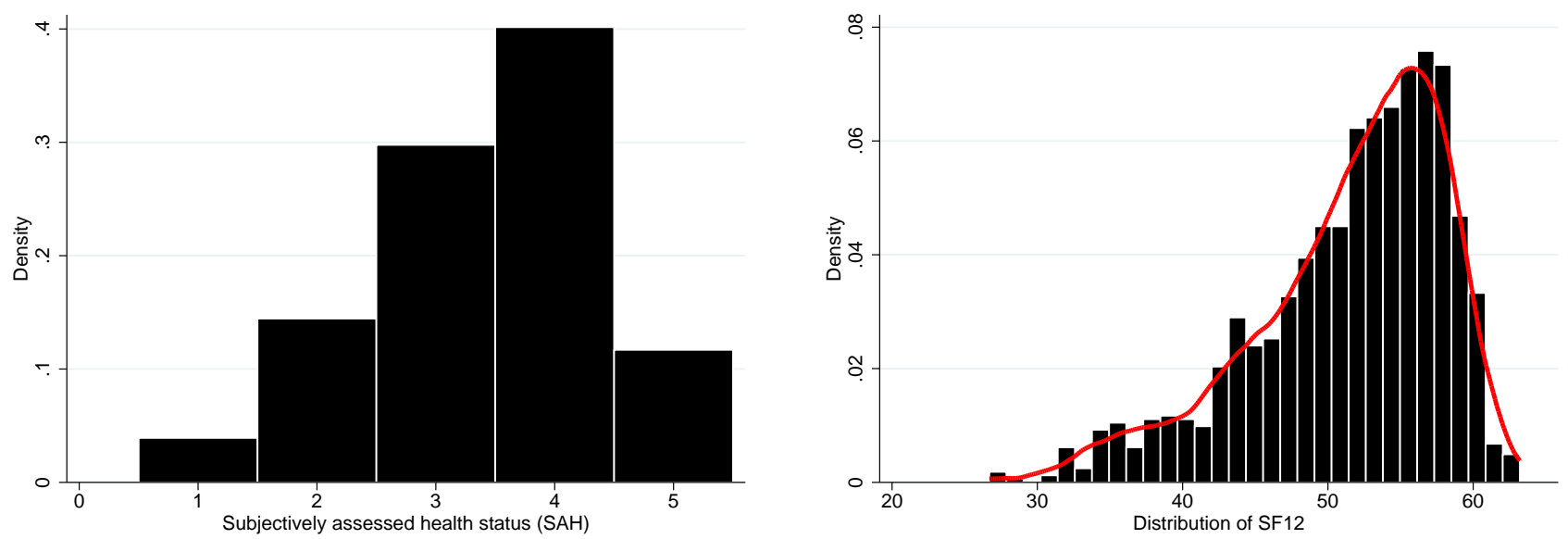
Figure A3: Distribution of $R_{i}$ Based on (a) SAH, (b) SF12 in BASE-II
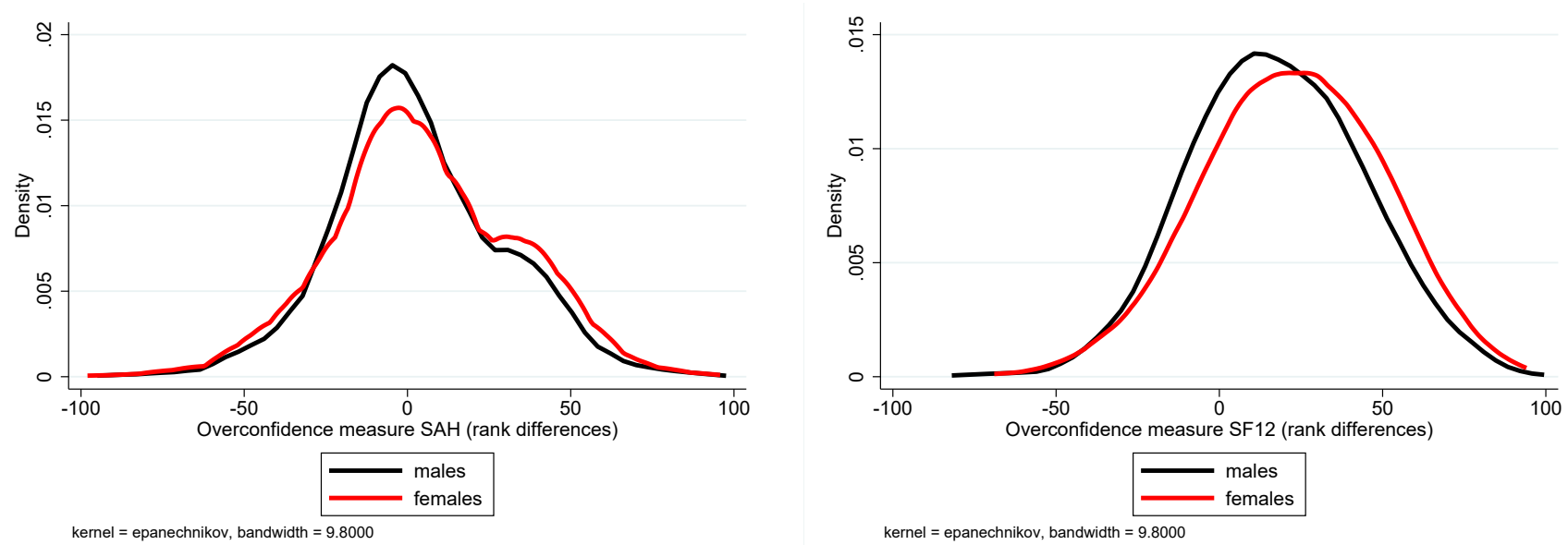

Source: BASE-II. Figure displays distributions of $R_{i}=\widetilde{r_{i}}-r_{i}$, with $\tilde{r_{i}}=1-\widetilde{b_{i}}$, see Figure 2 and main text. Subfigure (a) uses SAH and subfigure (b) uses the SF12 as $r_{i}$.

Table A1: German National Health Survey East-West 1991

\begin{tabular}{|c|c|c|c|c|c|}
\hline Variable & Mean & Std. Dev. & Min. & Max. & $\mathbf{N}$ \\
\hline \multicolumn{6}{|l|}{ A. Health Bias Measures } \\
\hline Absolute Health Bias Cholesterol, $A_{i}>1$ & 0.2976 & 0.4572 & 0 & 1 & 6429 \\
\hline Absolute Health Bias Blood Pressure, $A_{i}>1$ & 0.0935 & 0.2911 & 0 & 1 & 6429 \\
\hline \multicolumn{6}{|l|}{ B. Objective Health Measures $\left(H_{i}\right)$} \\
\hline Total blood cholesterol [mmol/l] & 6.128 & 1.2292 & 2.33 & 12.9 & 6429 \\
\hline High total blood cholesterol [ $>6.2 \mathrm{mmol} / \mathrm{l}]$ & 0.4394 & 0.4964 & 0 & 1 & 6429 \\
\hline Systole, 2. measure $[\mathrm{mmHg}]$ & 134.6558 & 20.2632 & 88 & 256 & 6429 \\
\hline Diastole, 2. measure [mmHg] & 83.4033 & 12.1276 & 34 & 158 & 6429 \\
\hline Hypertension & 0.2095 & 0.407 & 0 & 1 & 6429 \\
\hline \multicolumn{6}{|l|}{ C. Subjective Health Assessment $\left(\tilde{H}_{i}\right)$} \\
\hline High Cholesterol & 0.2072 & 0.4053 & 0 & 1 & 6429 \\
\hline High Blood Pressure & 0.2518 & 0.4341 & 0 & 1 & 6429 \\
\hline \multicolumn{6}{|l|}{ D. Health Behavior } \\
\hline Alcohol Daily & 0.1618 & 0.3683 & 0 & 1 & 6429 \\
\hline Current Smoker & 0.3282 & 0.4696 & 0 & 1 & 6429 \\
\hline Body-mass-index [kg per $\left.\mathrm{m}^{2}\right]$ & 26.6467 & 4.6113 & 15.02 & 75.467 & 6429 \\
\hline Obese $(\mathrm{BMI}>30)$ & 0.2019 & 0.4014 & 0 & 1 & 6429 \\
\hline No sports & 0.4652 & 0.4988 & 0 & 1 & 6429 \\
\hline
\end{tabular}

Sources: GNHSEW91, own illustration.[mmol/l] stands for millimole per liter. [mmHg] stands for millimetres of mercury. [kg per $\left.\mathrm{m}^{2}\right]$ stands for kilogram per square meter. 
Table A2: Descriptive Statistics BASE-II

\begin{tabular}{|c|c|c|c|c|c|}
\hline Variable & Mean & Std. Dev. & Min. & Max. & $\mathbf{N}$ \\
\hline \multicolumn{6}{|l|}{ A. Health Bias Measures } \\
\hline Relative Health Bias SAH, $R_{i}$ & 3.8770 & 26.2816 & -98 & 95.7662 & 1751 \\
\hline$R_{i}>0, \mathrm{SAH}$ & 11.9119 & 17.6585 & 0 & 95.7662 & 1751 \\
\hline$R_{i}<0, \mathrm{SAH}$ & 2.2780 & 10.0479 & 0 & 98 & 1751 \\
\hline Relative Health Bias SF12, $R_{i}$ & 19.9118 & 26.2824 & -72.5012 & 94.11023 & 1751 \\
\hline$R_{i}>0, \mathrm{SF} 12$ & 23.2566 & 21.3903 & 0 & 94.1102 & 1751 \\
\hline$R_{i}<0, \mathrm{SF} 12$ & 3.3443 & 8.8070 & 0 & 72.5012 & 1751 \\
\hline \multicolumn{6}{|l|}{ B. Health Behavior } \\
\hline BMI & 25.5181 & 4.3132 & 13.7143 & 64.0923 & 1780 \\
\hline Obese & 0.1264 & 0.3324 & 0 & 1 & 1780 \\
\hline Smoker & 0.1169 & 0.3213 & 0 & 1 & 1780 \\
\hline No sports & 0.3567 & 0.4792 & 0 & 1 & 1780 \\
\hline Unhealthy diet & 0.3866 & 0.4871 & 0 & 1 & 1780 \\
\hline \multicolumn{6}{|l|}{ C. Covariates } \\
\hline \multicolumn{6}{|l|}{ Demographics } \\
\hline Age & 60.0596 & 16.7442 & 18 & 89 & 1780 \\
\hline Female & 0.5242 & 0.4996 & 0 & 1 & 1780 \\
\hline Married & 0.5674 & 0.4956 & 0 & 1 & 1780 \\
\hline Single & 0.2528 & 0.4347 & 0 & 1 & 1780 \\
\hline Partner in Household & 0.6528 & 0.4762 & 0 & 1 & 1780 \\
\hline \# kids & 1.3118 & 1.1355 & 0 & 5 & 1780 \\
\hline \# daughters & 0.6573 & 0.8284 & 0 & 4 & 1780 \\
\hline No kids & 0.3101 & 0.4627 & 0 & 1 & 1780 \\
\hline German & 1.0124 & 0.1105 & 1 & 2 & 1780 \\
\hline \multicolumn{6}{|l|}{ Education } \\
\hline 8 school years & 0.1236 & 0.3292 & 0 & 1 & 1780 \\
\hline 10 school years & 0.2539 & 0.4354 & 0 & 1 & 1780 \\
\hline 13 school years & 0.5584 & 0.4967 & 0 & 1 & 1780 \\
\hline \multicolumn{6}{|l|}{ Employment } \\
\hline Blue collar worker & 0.0275 & 0.1637 & 0 & 1 & 1780 \\
\hline White collar worker & 0.1893 & 0.3919 & 0 & 1 & 1780 \\
\hline Civil servant & 0.0185 & 0.1349 & 0 & 1 & 1780 \\
\hline Full-time employed & 0.4697 & 0.4992 & 0 & 1 & 1780 \\
\hline Part-time employed & 0.1404 & 0.3476 & 0 & 1 & 1780 \\
\hline Gross labor earnings & 549.7449 & 1300.6576 & 0 & 20,000 & 1780 \\
\hline Net labor earnings (last month) & 378.4079 & 831.9664 & 0 & 10,000 & 1780 \\
\hline Total income (last month) & 1565.3478 & 1295.8649 & 0 & 20,950 & 1780 \\
\hline \multicolumn{6}{|l|}{ Behavioral Attitudes } \\
\hline Trust (in strangers) & 0.3966 & 0.4893 & 0 & 1 & 1780 \\
\hline Trust (general) & 0.7545 & 0.4305 & 0 & 1 & 1780 \\
\hline Risk aversion (scale) & 5.077 & 2.2269 & 0 & 10 & 1780 \\
\hline Risk averse & 0.2624 & 0.44 & 0 & 1 & 1780 \\
\hline Risk loving & 0.1528 & 0.3599 & 0 & 1 & 1780 \\
\hline No religion & 0.6348 & 0.4816 & 0 & 1 & 1780 \\
\hline \multicolumn{6}{|l|}{ Big Five } \\
\hline Openness & 4.9872 & 1.1524 & 1.3333 & 7 & 1780 \\
\hline Conscientiousness & 5.6126 & 0.9755 & 1.6667 & 7 & 1780 \\
\hline Extraversion & 4.7374 & 1.1743 & 1 & 7 & 1780 \\
\hline Neuroticism & 3.7723 & 1.2778 & 1 & 7 & 1780 \\
\hline Agreeableness & 5.2368 & 0.9820 & 1.3333 & 7 & 1780 \\
\hline
\end{tabular}


Table A3: Descriptive Statistics SOEP-IP

\begin{tabular}{|c|c|c|c|c|c|}
\hline $\begin{array}{l}\text { Variable } \\
\end{array}$ & Mean & Std. Dev. & Min. & Max. & $\mathbf{N}$ \\
\hline \multicolumn{6}{|l|}{ A. Health Bias Measures } \\
\hline Relative Health Bias SAH, $R_{i}$ & -0.2969 & 27.69 & -100 & 96.0114 & 1377 \\
\hline$R_{i}>0, \mathrm{SAH}$ & 10.234 & 16.9727 & 0 & 96.0114 & 1377 \\
\hline$R_{i}<0, \mathrm{SAH}$ & 4.256 & 14.1312 & 0 & 100 & 1377 \\
\hline Relative Health Bias SF12, $R_{i}$ & 13.8467 & 27.4498 & -96.2857 & 99 & 1377 \\
\hline$R_{i}>0, \mathrm{SF} 12$ & 18.917 & 20.6165 & 0 & 99 & 1377 \\
\hline$R_{i}<0, \mathrm{SF} 12$ & 5.0687 & 11.6833 & 0 & 96.2857 & 1377 \\
\hline \multicolumn{6}{|l|}{ B. Health Behavior } \\
\hline Sleep in hours, weekday & 6.8221 & 1.3144 & 2 & 13 & 1377 \\
\hline Sleep deficit, week & 1.1641 & 1.3151 & -5 & 6 & 1377 \\
\hline Sleep in hours, weekend & 7.5737 & 1.567 & 2 & 14 & 1377 \\
\hline Sleep deficit, weekend & 0.4242 & 1.5551 & -6 & 6 & 1377 \\
\hline \multicolumn{6}{|l|}{ C. Covariates } \\
\hline \multicolumn{6}{|l|}{ Demographics } \\
\hline Age & 51.1438 & 18.4188 & 17.011 & 93.2301 & 1377 \\
\hline Female & 0.5178 & 0.4999 & 0 & 1 & 1377 \\
\hline Married & 0.5272 & 0.4994 & 0 & 1 & 1377 \\
\hline Single & 0.2585 & 0.438 & 0 & 1 & 1377 \\
\hline \# kids & 0.5810 & 0.9436 & 0 & 5 & 1377 \\
\hline German & 0.9390 & 0.2394 & 0 & 1 & 1377 \\
\hline \multicolumn{6}{|l|}{ Education } \\
\hline 8 school years & 0.6572 & 0.4748 & 0 & 1 & 1377 \\
\hline 10 school years & 0.2012 & 0.401 & 0 & 1 & 1377 \\
\hline 13 school years & 0.1264 & 0.3324 & 0 & 1 & 1377 \\
\hline \multicolumn{6}{|l|}{ Employment } \\
\hline Blue collar worker & 0.0741 & 0.262 & 0 & 1 & 1377 \\
\hline White collar worker & 0.3471 & 0.4762 & 0 & 1 & 1377 \\
\hline Civil servant & 0.0312 & 0.174 & 0 & 1 & 1377 \\
\hline Full-time employed & 0.3573 & 0.4794 & 0 & 1 & 1377 \\
\hline Part-time employed & 0.1046 & 0.3061 & 0 & 1 & 1377 \\
\hline Gross labor earnings & 1293.5229 & 1836.4051 & 0 & 12,540 & 1377 \\
\hline Net labor earnings (last month) & 879.6253 & 1167.7447 & 0 & 8,000 & 1377 \\
\hline Total income (last month) & 1772.902 & 1736.4825 & 0 & 14,200 & 1377 \\
\hline \multicolumn{6}{|l|}{ Behavioral Attitudes } \\
\hline Risk averse & 0.3086 & 0.4621 & 0 & 1 & 1377 \\
\hline Risk loving & 0.1503 & 0.3575 & 0 & 1 & 1377 \\
\hline Risk Loving Health & 0.0763 & 0.2655 & 0 & 1 & 1377 \\
\hline Risk Averse Health & 0.5534 & 0.4973 & 0 & 1 & 1377 \\
\hline Risk Loving Trust & 0.0821 & 0.2746 & 0 & 1 & 1377 \\
\hline Risk Averse Trust & 0.4379 & 0.4963 & 0 & 1 & 1377 \\
\hline
\end{tabular}




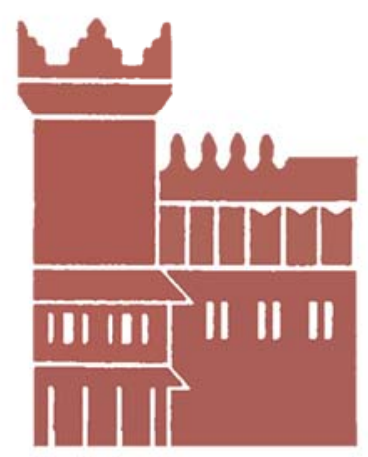

Alma Mater Studiorum - Università di Bologna DEPARTMENT OF ECONOMICS

Strada Maggiore 45

40125 Bologna - Italy

Tel. +39051 2092604

Fax +390512092664

http://www.dse.unibo.it 